\title{
Avaliação da resistência à antracnose em germoplasma de Lupinus spp.
}

\section{Evaluation of anthracnose resistance in Lupinus spp. germplasm}

\author{
Pedro Talhinhas*, João Neves-Martins e Helena Oliveira \\ LEAF-Linking Landscape, Environment, Agriculture and Food, Instituto Superior de Agronomia, Universidade de Lisboa. Lisboa, Portugal \\ (E-mail:ptalhinhas@isa.ulisboa.pt) \\ http://dx.doi.org/10.19084/RCA16096
}

Recebido/received: 2016.07.22

Recebido em versão revista/received in revised form: 2016.11.04

Aceite/accepted: 2016.11.24

\section{R E S U M O}

Uma das principais limitações à cultura de tremoceiros (pertencentes a várias espécies de Lupinus) em diversas partes do mundo resulta da sua suscetibilidade à antracnose, uma doença causada pelo fungo Colletotrichum lupini. Ao afetar o caule principal, esta doença pode causar a morte da planta, levando a perdas de produção frequentemente elevadas. A doença foi reportada apenas recentemente e a reduzida variabilidade genética do seu agente causal sugere uma origem recente do fungo. Pelo contrário, a grande riqueza genética encontrada no germoplasma de diversas espécies de Lupinus, algumas das quais tendo o território português como parte significativa da sua área de distribuição natural, impele estudos com vista à caracterização do grau de resistência a esta doença em acessos desse germoplasma. Após análise duma coleção de germoplasma contendo 51 acessos de Lupinus albus, 46 de L. angustifolius, 19 de L. luteus e 10 de L. mutabilis, através de inoculações em condições artificiais, foi identificado germoplasma de $L$. albus e de $L$. angustifolius com níveis promissores de resistência, respetivamente em variedades tradicionais e em germoplasma espontâneo português. O estudo do efeito da doença nos componentes da produção, em condições de campo, revelou que o número de vagens por infrutescência foi o componente da produção mais afetado, ilustrando um elevado aborto floral atribuído à doença. Estes resultados permitem uma utilização mais informada do germoplasma das espécies de Lupinus estudadas nos respetivos programas de melhoramento de plantas.

Palavras-chave: tremoceiro; Lupinus; Colletotrichum lupini; Colletotrichum acutatum; antracnose.

\section{A B S T R A C T}

Anthracnose, caused by the fungus Colletotrichum lupini, is one of the main limitations to the cultivation of several lupin species in different parts of the world. Affecting the main stem, this disease may cause plant death, leading to frequently high yield losses. This disease was reported only recently and the narrow genetic diversity of its pathogen suggests a recent origin for this fungus. On the contrary, the vast genetic richness found in the germplasm of diverse Lupinus species, some of them having the Portuguese territory as important component of their natural distribution areas, call for the study targeting the characterisation of disease resistance in such germplasm accessions. The analysis of a germplasm collection comprising 51 Lupinus albus, 46 L. angustifolius, 19 L. luteus and 10 L. mutabilis accessions using artificial inoculation conditions pointed out L. albus and L. angustifolius accessions with promising levels of resistance, on Portuguese landraces and wild germplasm respectively. Under field conditions, the effect of the disease on yield components affected mostly the number of pods per pod set, suggesting a high flower abortion due to the disease. These results enable a more informed use of the germplasm of these Lupinus species on the respective breeding programmes.

Keywords: lupin; Lupinus; Colletotrichum lupini; Colletotrichum acutatum; anthracnose. 


\section{INTRODUÇÃO}

A antracnose de Lupinus spp. foi diagnosticada originalmente por J. L. Weimer, nos E.U.A., em 1939, em Lupinus angustifolius (tremoço-de-folhasestreitas), sendo o agente causal identificado como Glomerella cingulata (Weimer, 1943), teleomorfo do fungo Colletotrichum gloeosporioides. Este autor cita duas referências anteriores à antracnose em tremoceiros (em 1912 no Brasil e em 1929 nos E.U.A.), mas sem que lhe tivesse sido possível confirmar tratar-se da mesma espécie. Em simultâneo com um incremento da cultura de $L$. angustifolius no Sudeste dos E.U.A., ocorreu um aumento da incidência e severidade da doença. Em 1952, após testar a resistência de diversas linhas de $L$. angustifolius à doença, J. Weimer identificou a existência de resistência em acessos selvagens portugueses. Posteriormente foi demonstrado tratar-se duma resistência monogénica dominante (Forbes e Wells, 1961) mas dependente da temperatura a que ocorre a infeção (Wells e Forbes, 1967), não se verificando infeção abaixo de $18^{\circ} \mathrm{C}$ (mesmo em linhas suscetíveis) e sendo todas as linhas afetadas acima de $28^{\circ} \mathrm{C}$. Em meados dos anos 50, a doença era comum em Portugal em diversas espécies de Lupinus, mas em geral de reduzida importância (Oliveira, 1955).

Mais tarde a doença reapareceu com importância internacional, em França em 1976 em L. mutabilis (tarwi ou tremoço-dos-Andes) e em 1982 em L. albus (tremoço) (Gondran et al., 1986), e na América do Sul no início dos anos 80, também em L. mutabilis e L. albus, sobretudo no Sul do Brasil, Chile e Peru (Baier e Linhares, 1991; Frey et al., 1993). Em França, Gondran (1984a) previu que a antracnose poderia tornar-se na mais importante doença de L. albus, pelo menos no que se refere às culturas de sementeira primaveril (Gondran, 1984b). Esta previsão veio a comprovar-se poucos anos depois, tanto para culturas de sementeira primaveril como outonal (Gondran, 1991). Também em tremoceiros ornamentais (L. polyphyllus e híbridos) se verificam importantes níveis de ataque, com perdas atingindo valores de 75\% (Reed et al., 1996).

Na última década do século 20 a antracnose assumiu grande importância, particularmente em climas mais húmidos. Causou a destruição total e o abandono da cultura de L. albus na Áustria, condicionou-a drasticamente na Alemanha (P. Römer, comunicação pessoal) e provocou fortes decréscimos de produção em França, Polónia, Rússia e Ucrânia (Gondran et al., 1999). A doença cresceu de importância de forma idêntica na América, causando maiores prejuízos no Brasil, Chile e Peru (von Baer e Hashagen, 1999), sendo também assinalada no Canadá (Paulitz, 1995). Na Oceânia, a doença foi diagnosticada pela primeira vez na Nova Zelândia em 1988, quando subitamente se verificou a destruição de 60 a 95\% das plantas da espécie perene $L$. arboreus utilizadas para estabilização de dunas costeiras (Dick, 1994). Para as espécies anuais, a doença assumiu proporções preocupantes em 1996/97 na Austrália, em L. albus pela maior susceptibilidade desta espécie e em $L$. angustifolius pela grande importância económica da cultura de plantas desta espécie, que na altura se encontrava em grande expansão, ultrapassando 1.000.000 ha, sobretudo na Austrália Ocidental (Cowling et al., 1998). A erradicação da doença foi na altura inviabilizada pela manutenção do inóculo em plantas espontâneas (anteriormente introduzidas) de L. cosentinii (Shea et al., 2008; Bennett et al., 2013). A doença foi assinalada na África do Sul em 1996 (van der Mey et al., 1996).

No início do século 21 a antracnose generalizouse em termos geográficos, tornando-se relevante em praticamente todas as regiões do mundo onde se cultivam plantas do género Lupinus (Nirenberg et al., 2002; Thomas e Sweetingham, 2004; Lotter e Berger, 2005; Thomas et al., 2008; Semaškienè et al., 2008; Riegel et al., 2010; Falconí et al., 2013; Talhinhas et al., 2016). Em Portugal, a doença é extremamente comum nos Açores em L. albus e L. luteus (tremocilha), apesar de ter sido possível recolher testemunhos que demonstram uma origem recente para um tão elevado nível de incidência e severidade (Talhinhas, 2002). Também em Portugal Continental foi possível registar a doença em L. albus em diversos locais na Beira Litoral, com ênfase para a sua maior prevalência no vale do Mondego.

\section{Sintomatologia}

A antracnose é uma doença que, em plantas de Lupinus spp., causa uma distorção típica de caules e pecíolos, formando lesões escuras em depressão (Figura 1), no centro das quais surgem acérvulos que, quando maduros, produzem conídios 
agregados em massas mucilaginosas de cor laranja. Estas lesões são mais frequentes nos caules, pecíolos e vagens. Nos caules e pecíolos, a distorção provocada chega a originar o total enrolamento do órgão sobre si próprio, uma situação sem paralelo noutras antracnoses (Sreenivasaprasad e Talhinhas, 2005). Com frequência, é no interior da curvatura que se formam as lesões necróticas. As sementes infetadas tornam-se manchadas de castanho, enrugadas, podendo mesmo exibir massas alaranjadas de esporos. Em geral mostramse incapazes de germinar, mas em casos de infeção limitada, a semente consegue germinar, exibindo lesões necróticas nos cotilédones ou no hipocótilo (Gondran e Pacault, 1997). Os sintomas são semelhantes em todas as espécies de Lupinus (Sweetingham et al., 1998b).

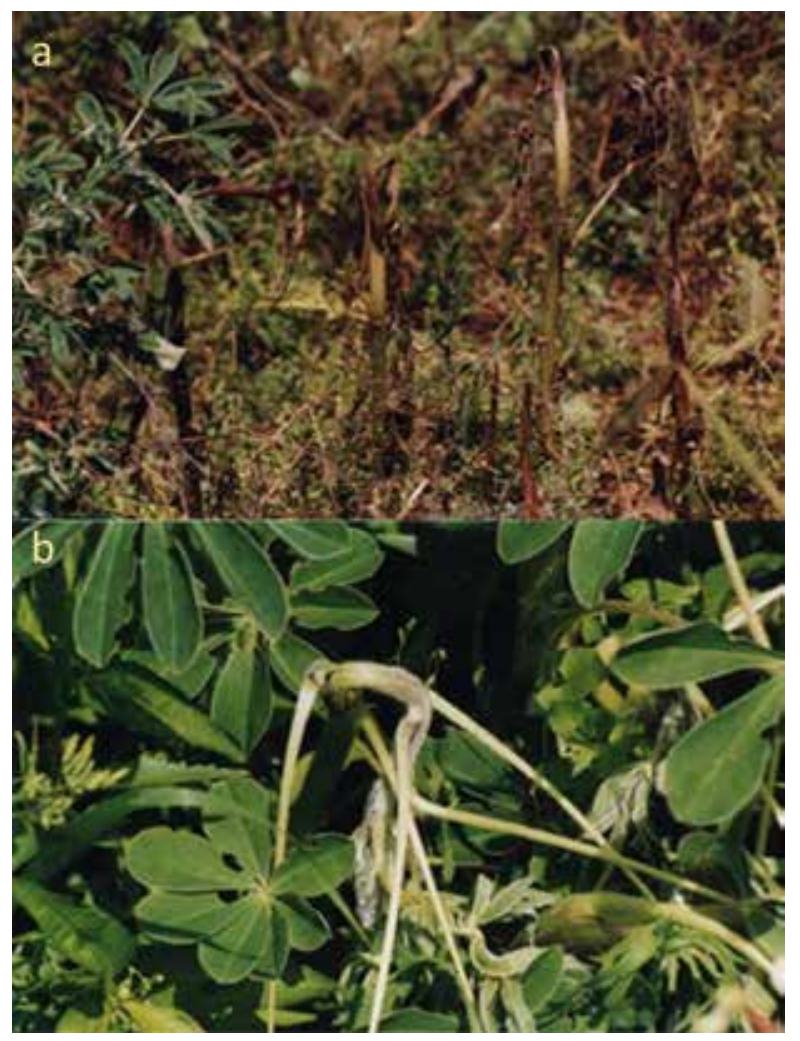

Figure 1 - Sintomas típicos de antracnose em Lupinus albus evidenciando: a) morte da planta após infeção severa e precoce; b) distorção e enrolamento do caule principal, após infeção mais tardia e menos severa que a anterior.

\section{Taxonomia}

O agente causal da atual epifitia de antracnose (iniciada nos anos 1970/80) foi identificado como pertencente a Colletotrichum acutatum Simmonds ex
Simmonds (Sreenivasaprasad et al., 1994; Gondran e Pacault, 1997; Lardner et al., 1999; Talhinhas et al., 2002). A diversidade genética existente entre fungos classificados como C. acutatum (Sreenivasaprasad e Talhinhas, 2005) levou ao reconhecimento desta como um complexo de espécies e, mais tarde, à promoção dos diversos grupos genéticos nela identificados à categoria de espécie (Damm et al., 2012), encontrando-se o agente causal da antracnose de Lupinus spp. atribuído à espécie C. Iupini (Bondar) Damm, P.F. Cannon \& Crous (Nirenberg et al., 2002; Damm et al., 2012). Estes e outros aspetos relacionados com a taxonomia do agente causal da antracnose de Lupinus spp. foram recentemente revistos (Talhinhas et al., 2016), pelo que não serão aprofundados neste trabalho.

\section{Biologia}

A transmissão da antracnose através das sementes de Lupinus spp., há muito demostrada (Decker, 1947), tem sido responsável pela disseminação do agente causal pelo mundo (Sweetingham et al., 1998b).

Condições de humidade saturante e temperaturas superiores a $10^{\circ} \mathrm{C}$ são suficientes para que se dê a infeção a partir de esporos do fungo. Mesmo infeções primárias surgindo numa planta em mil a dez mil podem originar infeções muito severas, dificultando uma correta e atempada deteção do agente causal e previsão da severidade da doença (Gondran e Pacault, 1997). Os esporos, uma vez aderidos à superfície vegetal, necessitam de humidade saturante durante $4 \mathrm{~h}$ a $24^{\circ} \mathrm{C}$ $\left(16 \mathrm{~h}\right.$ a $\left.12^{\circ} \mathrm{C}\right)$ para garantir a germinação e a penetração da epiderme. Após a penetração, dáse a colonização dos tecidos, sendo necessários oito dias a $24^{\circ} \mathrm{C}$ para a produção de novos esporos (16 dias a 12 $\mathrm{C}$ ) (Sweetingham et al., 1998c), em acérvulos (Figura 2). Noutros hospedeiros, o processo de infeção a partir de conídios de Colletotrichum spp. está muito melhor estudado que em Lupinus spp., conhecendo-se detalhes relativos à genética, bioquímica e histologia dos diversos passos que conduzem à colonização dos tecidos (adesão e germinação do esporo, produção e alongamento do tubo germinativo, formação, adesão e maturação do apressório, produção da pega de penetração, penetração da cutícula e desenvolvimento de diversos tipos de hifas inter- e intra-celulares) (Perfect et al., 1999; O'Connell et al., 2012). Perfect et al. (1999) definem 
dois tipos de estratégias de infeção para fungos do género Colletotrichum. Um corresponde a um desenvolvimento hemibiotrófico intracelular, com hifas especializadas desenvolvendo-se dentro das células do hospedeiro mas causando a invaginação do protoplasto vegetal, ou seja, sem romper ou penetrar a membrana celular vegetal, desenvolvendo posteriormente hifas necrotróficas, invasivas e destruidoras das células dos hospedeiros. Esta estratégia de colonização é seguida, por exemplo, por C. nymphaeae, um dos principais agentes causais da gafa da oliveira em Portugal (Talhinhas et al., 2011). A outra estratégia de infeção corresponde a um comportamento necrotrófico desde o início da invasão (sendo exemplo a infeção de Musa spp. por C. musae).

Regiões mais pluviosas são em geral mais favoráveis à doença, por ocorrerem, com maior frequência, condições favoráveis à dispersão dos conídios (pelos salpicos de chuva) e ao estabelecimento da infeção (humidade saturante) (Gondran e Pacault, 1997).

O restolho infetado pode ser uma fonte importante de inóculo, sobretudo em regiões de clima mediterrânico, em que não ocorre mineralização da matéria orgânica durante o Verão (Sweetingham et al., 1998b). A realização duma correta rotação torna-se assim importante para diminuir os riscos de ocorrência da doença.

A existência de plantas de Lupinus spp. espontâneas em terrenos vizinhos aos da cultura pode também servir como fonte de inóculo. A importância de outros hospedeiros como fatores de transmissão da antracnose a culturas de Lupinus spp. não se encontra ainda bem estabelecida, sendo no entanto reconhecido que isolados obtidos dum determinado hospedeiro são mais virulentos num hospedeiro da mesma espécie que doutra espécie (Gondran e Pacault, 1997). Foi também possível infetar plantas de L. angustifolius com outras espécies de Colletotrichum, tais como C. fragariae e C. trifolii (Welty, 1984), assim como L. arboreus com C. gloeosporioides f. sp. aeschynomene (Weidemann et al., 1988). Por sua vez, isolados obtidos de Lupinus spp. foram capazes de infetar pêssegos (Weimer e Dunegan, 1949), maçãs (Oliveira, 1955), tomates arbóreos (Falconí et al., 2013) e morangos (Baroncelli et al., 2015).

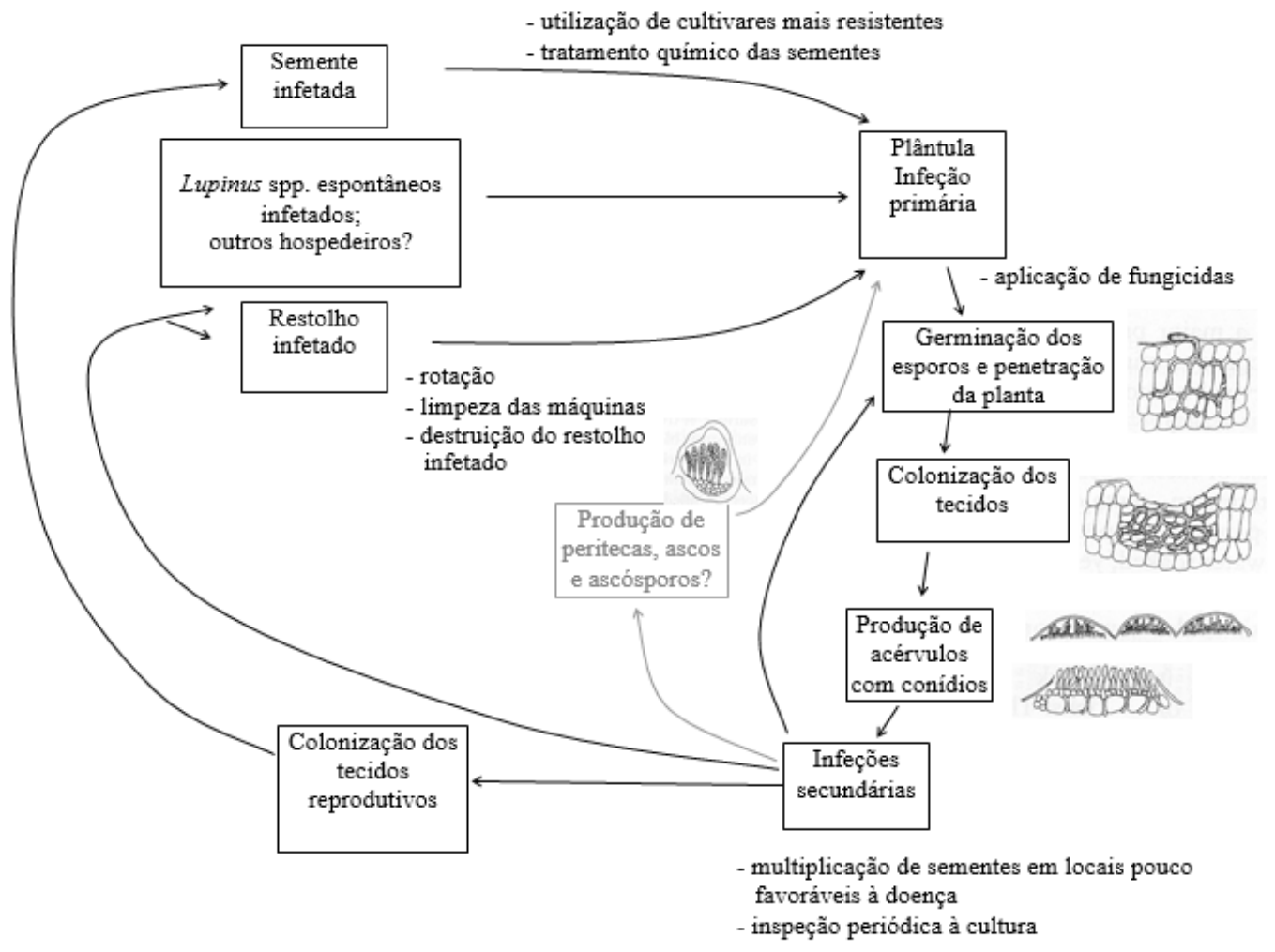

Figura 2 - Ciclo da antracnose em Lupinus spp. causada por Colletotrichum lupini com referência às principais medidas de controlo da doença (representações esquemáticas adaptadas de Agrios (1997)). 
A diferenciação de estruturas sexuadas não é clara para o agente causal da antracnose de tremoceiros. Na sua identificação original, Weimer (1943) observou e descreveu tanto acérvulos de C. gloeosporioides como peritecas de G. cingulata, a partir de lesões em caules de plantas infetadas. Também em Portugal, nos anos 50 do século 20, foi possível obter o teleomorfo em cultura a partir do isolamento do anamorfo no campo (Oliveira, 1955). No entanto, nenhum teleomorfo voltou a ser registado em qualquer outra posterior descrição até ao presente (Gondran e Pacault, 1997; Sweetingham et al., 1998b; Talhinhas et al., 2016). A repartição de isolados por diferentes Grupos de Compatibilidade Vegetativa, correspondendo um destes grupos a isolados de menor virulência e em parte oriundos da América do Norte, levou à sugestão de que estes seriam descendentes diretos da epifitia dos anos 40/50 (Shivas et al., 1998), no entanto sem que tenha sido observado o teleomorfo.

\section{Resistência de Lupinus à antracnose}

Após a antracnose se ter tornado pela primeira vez uma doença importante em L. angustifolius, foi encontrada resistência em germoplasma selvagem português e esta introduzida em cultivares. Nessa altura, as cultivares de L. albus testadas (Weimer, 1943) mostraram-se suscetíveis à doença, não se tendo encontrado qualquer resistência.

Quando a doença voltou a tornar-se preocupante, nos anos 80 do século 20 , a severidade foi maior em $L$. albus e L. mutabilis, mas com suscetibilidade também em L. angustifolius e L. luteus (Sweetingham et al., 1998b). As cultivares de L. angustifolius, resistentes à epifitia inicial não se mostraram resistentes à nova epifitia (Sweetingham et al., 1998a). Os testes de inoculação de germoplasma para avaliação de resistência iniciaram-se em França em 1986 (Gondran et al., 1991) e no Brasil em 1988 (Baier e Linhares, 1991). Alguns ensaios de comparação de variedades mostraram a existência de variabilidade para a resistência à doença. Algumas linhas menos suscetíveis são: em L. albus, as cultivares 'Rumbo' (von Baer e Hashagen, 1999), 'Victoria' (Gondran et al., 1999), 'Prima', 'Lolita' (Galdames e Peñaloza, 1999), 'Cruz Alta' (Baier e Linhares, 1991), 'LA128' (Gondran et al., 1991), 'Andromeda' (Adhikari et al., 2009), 'Amira' (Adhikari et al., 2013) e linhas de melhorador sul-africanas não identificadas (van der Mey et al., 2000); em L. angustifolius, uma linha não identificada (Galdames e Peñaloza, 1999) e as cultivares 'Borweta' (Semaškienè et al., 2008), 'Wonga' e 'Tanjil' (Sweetingham et al., 1998a; Cowling et al., 2000). No entanto, nenhuma destas linhas foi considerada como totalmente resistente. Verifica-se também que, até à realização do presente estudo, a pesquisa de resistência foi feita sobretudo em cultivares, descurando em certa medida o germoplasma tradicional e selvagem, aliás de onde surgiu a resistência à epifitia dos anos 40 do século 20 .

O presente trabalho visa contribuir para identificar linhas resistentes que possam ser usadas, quer diretamente em cultura, quer como fonte deste carácter para inclusão em programas de melhoramento. Para tal, procedeu à avaliação da resistência à antracnose de acessos de Lupinus spp. conservados no Banco de Germoplasma do Instituto Superior de Agronomia tomando em consideração a diversidade genética morfológica e molecular verificada entre estes acessos de Lupinus spp. (Talhinhas et al., 2003, 2006), bem como com a diversidade genética verificada entre isolados do agente causal da doença (Talhinhas et al., 2002, 2016). Pretendeu-se por outro lado identificar acessos suscetíveis que, contrastando com os resistentes, possam ser usados em estudos visando esclarecer o determinismo genético do carácter resistência à antracnose.

Para a prossecução destes objetivos realizaramse diversos ensaios de inoculação do fungo em plantas de Lupinus spp., tanto em estufa como em campo, observando-se o comportamento das plantas à luz de escalas de severidade de doença estabelecidas para o efeito. Este estudo incidiu sobretudo em acessos de L. albus e L. angustifolius, mas também de L. luteus e L. mutabilis.

\section{MATERIAIS E MÉTODOS}

\section{Otimização de condições experimentais}

Antes de proceder aos ensaios de inoculação dos acessos de germoplasma em estufa em larga escala, procedeu-se a estudos visando otimizar as condições de crescimento das plantas, inoculação, incubação e avaliação dos resultados. Os fatores objeto de análise foram: idade da planta, método 
de inoculação, número de dias desde a inoculação à avaliação de sintomas e severidade da doença.

\section{Idade da planta}

Foram analisadas plantas de 4-5 folhas e plantas de 7-8 folhas. Foram testadas duas cultivares de $L$. angustifolius (10196, 'Unicrop' e 10158, 'Illyarrie') e uma variedade tradicional de L. albus (acesso 00252, de Rio Maior), assim como três isolados de $C$. lupini, o isolado C.G.Canada (obtido de L. albus no Canadá) sugerido como representante da epifitia americana dos anos 40/50 (Shivas et al., 1998) e os isolados G52 (obtido de L. albus na Alemanha) e 96A4 (obtido de L. angustifolius na Austrália) representando a atual epifitia. Como controlo negativo utilizou-se água destilada esterilizada em substituição dos esporos do fungo. Foram testadas todas as combinações dos diversos níveis dos três fatores em estudo (idade da planta, acesso e isolado), considerando-se cinco repetições por combinação. As plantas foram pulverizadas com uma suspensão conidial de cada um dos isolados doseando aproximadamente $8 \times 10^{5}$ esporos.mL $\mathrm{m}^{1}$, tal como descrito mais pormenorizadamente em seguida. Após a inoculação, as plantas foram mantidas a $100 \%$ de humidade relativa, na obscuridade, a $25^{\circ} \mathrm{C}$, regressando a condições de estufa após $48 \mathrm{~h}$. Os resultados foram observados 11 dias após a inoculação e a severidade da doença avaliada segundo uma escala de sintomas (Quadro 1).

\section{Método de inoculação e duração do período de humidade saturante}

Testaram-se três métodos alternativos de inoculação das plantas, dois incidindo sobre a planta inteira e um visando órgãos destacados. Além da metodologia preconizada por Gondran et al. (1999), envolvendo a pulverização duma suspensão de esporos sobre as plantas, realizouse também a inoculação por deposição duma gota de suspensão de esporos sobre ferida realizada no caule (Bhaskara Reddy et al., 1996), assim como a inoculação por pulverização de suspensão de esporos sobre uma folha destacada, mantida em condições de humidade saturante em placa de Petri (Tu, 1986), o que permitiria fazer estudos não destrutivos para a planta. Em qualquer dos casos, a suspensão continha cerca de $8 \times 10^{5}$ esporos.mL-1 do isolado $96 \mathrm{~A} 4$ e $2 \%(\mathrm{p} / \mathrm{v})$ de gelatina para facilitar a adesão das gotículas às superfícies vegetais. As restantes condições de incubação foram idênticas às descritas para o estudo da idade da planta mais favorável à inoculação.

Para o ensaio de inoculação de folhas destacadas foram usadas folhas jovens (recém-expandidas) e adultas (terceira ou quarta folha expandida duma planta com 7-8 folhas) de L. albus (acesso 00252, de Rio Maior) e L. angustifolius (acesso 10158, 'Illyarrie'), inoculadas com uma suspensão de esporos obtida a partir de culturas do isolado 96A4. As folhas foram destacadas cortando-se o pecíolo a meio, inoculadas por pulverização e colocadas em placa de Petri com papel de filtro disposto sobre algodão humedecido, onde foram mantidas a $25^{\circ} \mathrm{C}$ com fotoperíodo diário de $14 \mathrm{~h}\left(150 \mu \mathrm{E} \cdot \mathrm{m}^{-2} \cdot \mathrm{s}^{-1}\right)$.

Em simultâneo com o método de inoculação, testou-se a duração do período em que as plantas são mantidas em condições de humidade saturante: $0 \mathrm{~h}, 24 \mathrm{~h}, 48 \mathrm{~h}$ e ao longo de todo o período de incubação (11 dias). Foram realizados dois ensaios, tendo-se alterado ligeiramente o protocolo de inoculação por ferida, entre um ensaio e outro.

Num primeiro ensaio testou-se o método de pulverização da suspensão de esporos, em comparação com a aplicação de gota de suspensão de esporos em ferida no caule (lesão feita no epicótilo com bisturi esterilizado), tendo-se

Quadro 1 - Escala de sintomas usada na avaliação da resistência de plantas de Lupinus spp. à antracnose (adaptada de J. Gondran, comunicação pessoal) (R, Resistente; S, Suscetível)

\begin{tabular}{lll}
\hline \multicolumn{2}{l}{ Notação } & Sintomas \\
\hline \multirow{3}{*}{$\mathbf{R}$} & 0 & sem sintomas \\
& 1 & sintomas apenas nas folhas \\
& 2 & sintomas nos pecíolos e/ou estípulas sem atingir o meristema \\
\hline \multirow{3}{*}{$\mathbf{S}$} & 3 & meristema ou caule atacados mas poucos sintomas no resto da planta \\
& 4 & meristema ou caule atacados com importantes lesões no resto da planta \\
& 5 & planta morta ou quase (reduzida área verde) \\
\hline
\end{tabular}


também incluído um controlo negativo para cada um dos métodos, substituindo o inóculo por água destilada esterilizada. Estudaram-se dois acessos de L. albus, 00280 ('Victoria') e 00288 ('Kiev Mutant'), e quatro períodos de humidade saturante $(0 \mathrm{~h}, 24$ h, 48 h e contínuo até à observação dos sintomas), sendo as restantes condições idênticas às referidas para o estudo da idade da planta. Foram efetuadas cinco repetições para cada combinação de fatores.

Num segundo ensaio, a ferida, em vez de ser feita com bisturi, foi efetuada com uma agulha, por forma a homogeneizar a dimensão das lesões. Foram incluídos acessos de L. angustifolius (10196, 'Unicrop' e 10163, 'Kalya'), restringiu-se o estudo da duração do período de humidade saturante a dois níveis (48 h e até ao momento da observação dos sintomas) e estabeleceu-se uma nova escala para registar os sintomas apresentados pelas plantas inoculadas pelo método da ferida, em que as plantas classificadas de 0 a 2 foram consideradas resistentes e entre 3 e 5 suscetíveis (Quadro 2).

\section{Duração do período de incubação da antracnose}

Qualquer dos ensaios de otimização de condições anteriormente descritos foi usado para estudar este fator, registando-se os sintomas apresentados pelas plantas, segundo a escala referida no Quadro 1 ao $4^{\circ}, 7^{\circ}, 11^{\circ}, 15^{\circ}$ e $18^{\circ}$ dias após a inoculação.

\section{Ensaios em estufa}

No que se refere à resistência à antracnose em condições de estufa, analisaram-se 51 acessos de L. albus (Quadro 6), 46 de L. angustifolius (Quadro 7), 19 de L. luteus (Quadro 8) e 10 de L. mutabilis (Quadro 9), pertencentes ao banco de germoplasma do ISA.

\section{Condições de crescimento das plantas}

As plantas foram cultivadas em vasos individuais (volume de cerca de 0,5 L) contendo uma mistura
1:1:1 de terra:turfa:areia. Imediatamente antes da sementeira, as sementes foram desinfetadas por imersão durante 15 min numa solução aquosa de $\mathrm{NaClO}$ a $1 \%$, sendo depois lavadas com água durante pelo menos outros $15 \mathrm{~min}$. As plantas foram mantidas em estufa de campo à temperatura aproximada de $25^{\circ} \mathrm{C}$ e uma luminosidade de 200 a $300 \mu \mathrm{E} \cdot \mathrm{m}^{-2} \cdot \mathrm{s}^{-1}$, convenientemente regadas e inoculadas na fase de 4-5 folhas.

\section{Produção de inóculo}

Para a produção de inóculo, utilizaram-se culturas monospóricas do isolado 2 de C. lupini (obtido de plantas de L. albus, em Montemor-o-Velho) com sete dias de idade, crescendo em placas de Petri de poliestireno de $9 \mathrm{~cm}$ de diâmetro, contendo gelose de batata dextrosada, PDA (Difco), a $25^{\circ} \mathrm{C}$ em condições de obscuridade. Produziu-se uma suspensão de esporos por inundação da placa com água destilada esterilizada, raspagem com uma ansa para libertar os esporos e filtração (filtro malha $\mathrm{n}^{\circ} 1$ Brand) para reter fragmentos de micélio. A concentração da suspensão foi ajustada para um valor final de cerca de $8 \times 10^{5}$ esporos. $\mathrm{mL}^{-1}$ (J. Gondran, comunicação pessoal; Galdames e Peñaloza, 1999). A suspensão final incluía gelatina a $2 \%(\mathrm{p} / \mathrm{v})$ como agente molhante (adaptado e otimizado a partir de Gondran et al., 1999).

A inoculação foi realizada por pulverização da suspensão sobre a parte aérea das plantas, recorrendo a um pulverizador manual (Gondran e Pacault, 1997).

\section{Condições de incubação}

Imediatamente após a inoculação e durante 48 h, as plantas foram mantidas em condições de humidade saturante, a $25^{\circ} \mathrm{C}$, em câmara de crescimento (Bioclima 750, Aralab), na obscuridade. Findo este período, as plantas regressaram à estufa (sujeitas às condições atrás referidas de temperatura e

Quadro 2 - Escala de sintomas usada na avaliação da severidade da doença causada em plantas de Lupinus spp. pelo fungo (Colletotrichum sp.) quando inoculadas por ferida (R, Resistente; S, Suscetível)

\begin{tabular}{lll}
\hline Notação & & Sintomas \\
\hline \multirow{3}{*}{$\mathbf{R}$} & 0 & ferida cicatrizada \\
& 1 & necrose expandida apenas verticalmente \\
& 2 & necrose expandida lateralmente, envolvendo até $50 \%$ do perímetro do caule \\
\hline \multirow{3}{*}{$\mathbf{S}$} & 3 & necrose envolvendo mais de $50 \%$ do perímetro do caule mas o caule ereto \\
& 4 & caule ereto mas dobrável por toque \\
& 5 & caule dobrado e/ou planta totalmente senescente \\
\hline
\end{tabular}


luminosidade) e já não sujeitas a condições de humidade saturante.

\section{Avaliação da suscetibilidade}

A observação dos sintomas e da severidade da doença foi efetuada 11 dias após a inoculação, segundo uma escala de 0 a 5 , sendo consideradas como resistentes as plantas classificadas de 0 a 2 e suscetíveis as plantas classificadas de 3 a 5 (Quadro 1; adaptado de J. Gondran, comunicação pessoal).

\section{Análise estatística}

$\mathrm{Na}$ análise de dados considerou-se um único fator (acesso) com tantos níveis quantos os acessos de cada espécie. Tomaram-se 10 repetições por acesso. Considerando o delineamento totalmente casualisado, os resultados obtidos para os diversos acessos foram comparados entre si com recurso a ANOVA a um fator, seguida de testes de comparação de médias (Tukey, 95\% de confiança), usando o programa Statistica 8.0 (StatSoft Inc. 2008).

\section{Ensaio de campo}

Este ensaio teve lugar na Tapada da Ajuda, Lisboa ( $38^{\circ} 42^{\prime}$ N, 9o 11’ O, 60 m), num talhão de aparência homogénea, sem declive. Teve como objetivo observar o efeito da infeção nos componentes da produção e na distribuição da produção de semente nos diversos andares produtivos da planta, criando condições de inoculação artificial, por comparação com plantas não inoculadas.

Foram utilizados sete acessos de L. albus, escolhidos em função de outros resultados previamente obtidos, sendo considerados os acessos 00140 (variedade tradicional de Bunheiro, Murtosa), 00190 (variedade tradicional de Salamanca, Espanha) e 00280 (cultivar chilena 'Victoria') como representantes dos mais resistentes, os acessos 00252 (de Rio Maior), 00208 (linha de melhorador francesa LA300) e 00230 (cultivar portuguesa 'Misak') como representantes dos mais suscetíveis, figurando o acesso 00126 (variedade tradicional açoreana) numa posição intermédia.

Os sete acessos foram cultivados sob as seguintes três modalidades:

1 - pulverização duma suspensão de aproximadamente $8 \times 10^{5}$ esporos. $\mathrm{mL}^{-1}$ (isolado 2 de C. lupini, obtido de L. albus em
Montemor-o-Velho) seguida de manutenção de condições propícias à infeção;

2 - controlo negativo, em tudo idêntico à modalidade inoculada com o fungo, com a exceção da suspensão de esporos ser substituída por água destilada esterilizada;

3 - plantas não inoculadas nem mantidas em condições propícias à infeção, antes sujeitas às condições ambientais naturais.

4 - Para cada combinação 'modalidade' × 'acesso' foram efetuadas quatro repetições (duas para a modalidade 2), cada uma constituída por uma linha de sementeira de 1,5 m (10 cm entre plantas na linha; entrelinha de $40 \mathrm{~cm}$ ). Cada talhão foi rodeado por uma bordadura de plantas da variedade tradicional Rio Maior de L. albus semeada 14 dias antes da sementeira do ensaio, por forma a garantir algum isolamento físico entre os talhões.

A produção de inóculo foi efetuada como anteriormente referido. Para a manutenção de condições de humidade favoráveis à doença, os talhões correspondentes às modalidades 1 e 2 foram cobertos por manga plástica durante sete dias, após o que foram mantidas condições de humidade por regas por aspersão frequentes. $\mathrm{O}$ talhão correspondente à modalidade 3 foi mantido sob condições ambientais normais, nunca se tendo verificado a ocorrência de humidade relativa superior a $95 \%$ por períodos superiores a um dia.

O ensaio foi semeado em Novembro e a inoculação realizada à floração dos acessos mais tardios, em Março.

À colheita, foram avaliados os componentes da produção em cada nível produtivo para dez plantas de cada linha. Os dados obtidos foram submetidos a ANOVA segundo um delineamento a dois fatores, seguida de testes de comparação de médias (Tukey, 95\%). As condicionantes práticas de que se revestiu o ensaio (nomeadamente a necessidade de manter alguns talhões em condições favoráveis à doença) impossibilitou a aleatorização de cada combinação 'modalidade' x 'acesso', levando a considerar a variável 'acesso' subordinada à variável 'modalidade'. 


\section{RESULTADOS}

\section{Otimização de condições}

\section{Idade da planta}

O ensaio realizado para analisar a idade da planta ótima para o estudo de inoculação do germoplasma originou os resultados apresentados no Quadro 3. Verificou-se que a fase de 4 a 5 folhas é a mais indicada para realizar as inoculações, ao permitir que as plantas (de qualquer dos três acessos) estejam desenvolvidas o suficiente para nelas se poderem observar diferentes níveis de severidade da doença (para qualquer dos três isolados) e, simultaneamente, evitando a acumulação de problemas, tais como mortalidade e desfasamentos no desenvolvimento, que ocorrem para plantas mais velhas e que aumentam a variabilidade dos resultados, tal como ilustrados pelos desvios padrões superiores obtidos em plantas com 7 a 8 folhas.

Método de inoculação e duração do período de humidade saturante

A inoculação de folhas destacadas mantidas em condições de humidade não permitiu a obtenção de quaisquer sintomas sobre as folhas. Ao fim de 15 dias de incubação, as folhas mantinhamse túrgidas e verdes, após o que iniciavam um processo de senescência sem no entanto exibirem sintomas típicos de antracnose.
Quadro 3 - Média e desvio padrão da notação atribuída à severidade da doença (escala de 0 a 5; Quadro 1) em plantas de três acessos de Lupinus spp. inoculados com três isolados diferentes de Colletotrichum lupini em duas fases diferentes do desenvolvimento das plantas

\begin{tabular}{cccc}
\hline Acesso & $\begin{array}{c}\text { Isolado } \\
\text { a }\end{array}$ & $\begin{array}{c}\text { 4-5 folhas } \\
\text { (média e desv pad) }\end{array}$ & $\begin{array}{c}\text { 7-8 folhas } \\
\text { (média e desv pad) }\end{array}$ \\
\hline 00252 & 0 & $0,00 \pm 0,00$ & $0,00 \pm 0,00$ \\
Rio Maior & 4 & $3,80 \pm 1,15$ & $3,17 \pm 1,61$ \\
(L. albus) & 6 & $4,40 \pm 0,55$ & $3,33 \pm 2,08$ \\
& 9 & $4,50 \pm 0,71$ & $3,00 \pm 1,41$ \\
\hline 10196 & 0 & $0,00 \pm 0,00$ & $0,00 \pm 0,00$ \\
'Unicrop' & 4 & $4,00 \pm 0,82$ & $1,80 \pm 1,64$ \\
(L. angustifolius) & 6 & $3,83 \pm 1,26$ & $1,60 \pm 1,14$ \\
& 9 & $2,00 \pm 1,63$ & $1,75 \pm 2,06$ \\
\hline 10158 & 0 & $0,00 \pm 0,00$ & $0,00 \pm 0,00$ \\
'Illyarrie' & 4 & $3,50 \pm 1,73$ & $1,33 \pm 1,53$ \\
(L. angustifolius) & 6 & $3,00 \pm 1,63$ & $2,75 \pm 2,63$ \\
& 9 & $3,00 \pm 2,00$ & $2,75 \pm 2,06$ \\
\hline
\end{tabular}

a 0 controlo negativo (plantas pulverizadas com água destilada esterilizada em substituição do fungo) é identificado com o algarismo zero.

Para o estudo da inoculação de plantas inteiras, o primeiro ensaio mostrou que os sintomas decorrentes da infeção, usando o método de inoculação por ferida, não puderam ser avaliados de acordo com a escala previamente estabelecida. Verificou-se que, usando este método, os resultados se mostraram variáveis consoante a profundidade da lesão efetuada com bisturi. Ainda assim permitiu observar que a duração do período de humidade saturante não originou diferenças nos resultados

Quadro 4 - Média e desvio padrão da notação atribuída à severidade da doença (escala de 0 a 5; Quadro 1) causada pelo isolado 96A4 de Colletotrichum lupini, em acessos de Lupinus albus, obtida para cada acesso, modalidade e duração do período de humidade saturante (ensaio 1)

\begin{tabular}{lccc}
\hline Modalidade & $\begin{array}{c}\text { Duração (h) } \\
\text { da humidade } \\
\text { saturante }\end{array}$ & $\begin{array}{c}00280 \\
\text { 'Victoria' } \\
\text { média e desv. pad. }\end{array}$ & $\begin{array}{c}\text { 00288 'Kiev } \\
\text { Mutant' } \\
\text { média e desv. pad. }\end{array}$ \\
\hline Inoculação & 0 & $0,20 \pm 0,45$ & $0,60 \pm 0,89$ \\
(isolado 96A4) & 24 & $1,50 \pm 0,87$ & $2,80 \pm 1,10$ \\
& 48 & $2,10 \pm 1,24$ & $3,20 \pm 1,10$ \\
& sempre $^{\text {a }}$ & $2,40 \pm 0,89$ & $2,80 \pm 1,10$ \\
\hline Testemunha & 0 & $0,00 \pm 0,00$ & $0,00 \pm 0,00$ \\
(água) & 24 & $0,00 \pm 0,00$ & $0,00 \pm 0,00$ \\
& 48 & $0,00 \pm 0,00$ & $0,00 \pm 0,00$ \\
& sempre $^{\text {a }}$ & $0,00 \pm 0,00$ & $0,00 \pm 0,00$ \\
\hline
\end{tabular}

a Onze dias, até à observação dos sintomas. 
e que o método de inoculação por ferida produz infeções úteis para proceder a reisolamentos. Para o método de pulverização, apresentam-se no Quadro 4 os resultados das inoculações efetuadas. Verificou-se um aumento da severidade da doença entre os períodos de $0 \mathrm{~h}, 24 \mathrm{~h}$ e $48 \mathrm{~h}$ de humidade saturante, mas tais diferenças já não surgem quando se comparam os períodos de $48 \mathrm{~h}$ e até à observação dos sintomas. Adotou-se assim a utilização de períodos de incubação de 48 h para os diversos ensaios.

No segundo ensaio, onde a inoculação sobre ferida foi realizada após lesionar o epicótilo com agulha esterilizada, a escala de severidade da doença para tal estabelecida (Quadro 2) permitiu a observação dos resultados reportados no Quadro 5. Os resultados não sugerem diferenças significativas entre os métodos de inoculação, se bem que a inoculação sobre ferida tenha originado resultados mais variáveis que a inoculação por pulverização. A comparação dos períodos de humidade saturante de 48 h e contínua até à observação dos sintomas mostrou, tal como no ensaio anterior, a inexistência de importantes diferenças entre a duração daqueles dois períodos.

Considerando os resultados obtidos, adotou-se a inoculação por pulverização com um período de incubação de $48 \mathrm{~h}$ para o estudo generalizado da coleção de germoplasma.

Número de dias da inoculação à avaliação dos sintomas

Verificou-se que, cerca de 11 dias após a inoculação, os sintomas atingem o máximo de discriminação entre acessos. Para períodos superiores verificase que se acumula o efeito de fatores ambientais aleatórios sobre as plantas, além do facto de estas começarem a ser limitadas no seu crescimento pelo volume de substrato de que dispõem.

\section{Ensaios em estufa}

As inoculações em estufa originaram respostas diferenciadas da parte das diversas espécies e acessos em estudo. Em L. albus, os valores médios (conjuntos de dez plantas) de severidade da doença oscilaram entre 1,1 e 5,0, com uma média geral de 3,2. De um total de 51 acessos em análise, nove foram classificados como resistentes (valores médios de severidade de 0-2), enquanto 43 foram classificados como suscetíveis (valores médios de severidade de 3-5), ainda que, e de acordo com os testes estatísticos realizados, diversos acessos classificados como resistentes não podem ser considerados significativamente diferentes de outros classificados como suscetíveis. Procedendo a ANOVA e a testes de comparação de médias, verifica-se a existência de diferenças significativas entre os acessos em estudo no que se refere à resistência à antracnose (Quadro 6).

Os acessos de L. albus classificados como resistentes são originários de diversos países. Destacamse duas variedades tradicionais espanholas (acessos 00120 e 00190), duas cultivares alemãs (acessos 00248 'Petkuser' e 00263 'SWS St. 786'), a cultivar chilena 'Prima' (acesso 00249), uma linha de melhorador sul-africana (acesso 00257) e uma variedade tradicional portuguesa oriunda

Quadro 5 - Média e desvio padrão da notação atribuída à severidade da doença (escala de 0 a 5; quadro 2) causada pelo isolado 96A4 de Colletotrichum lupini, em acessos de Lupinus spp., em função do método de inoculação, produto pulverizado e duração do período de humidade saturante (ensaio 2)

\begin{tabular}{llcccc}
\hline Método de & $\begin{array}{l}\text { Duração (h) } \\
\text { inoculação } \\
\text { da }\end{array}$ & \multicolumn{3}{c}{ Lcesso } \\
\cline { 3 - 6 } & $\begin{array}{l}\text { humidade } \\
\text { saturante }\end{array}$ & $\begin{array}{c}00280 \\
\text { 'Victoria' } \\
\text { média e desv. pad. }\end{array}$ & $\begin{array}{c}00288 \text { 'Kiev } \\
\text { Mutant' } \\
\text { média e desv. pad. }\end{array}$ & $\begin{array}{c}\text { 'Unicrop' } \\
\text { média e desv. pad. }\end{array}$ & $\begin{array}{c}10196 \\
\text { média e desv. pad. }\end{array}$ \\
\hline Pulverizaçã & 48 & $3,70 \pm 0,27$ & $3,00 \pm 0,00$ & $4,70 \pm 0,45$ & $3,75 \pm 0,87$ \\
o & & & & & \\
& & & $3,50 \pm 0,35$ & $5,00 \pm 0,00$ & $4,12 \pm 0,85$ \\
\hline Ferida & 48 & $4,40 \pm 0,89$ & $3,30 \pm 1,20$ & $4,40 \pm 0,89$ & $4,17 \pm 1,04$ \\
& sempre $^{\text {a }}$ & $3,60 \pm 0,96$ & $3,20 \pm 1,48$ & $3,80 \pm 0,45$ & $4,50 \pm 0,58$ \\
\hline
\end{tabular}

a Onze dias, até à observação dos sintomas. 
Quadro 6 - Médias e grupos homogéneos (teste de Tukey, 95\%) para a severidade da infeção causada por Colletotrichum lupini (isolado 96A4) em acessos de Lupinus albus

\begin{tabular}{|c|c|c|c|c|c|c|c|c|c|c|c|c|}
\hline Ref. & Nome & País ${ }^{\mathrm{a}}$ & Local & Tipo $^{b}$ & Média & \multicolumn{7}{|c|}{$\begin{array}{c}\text { Gr. } \\
\text { Homogéneos }^{\mathrm{c}}\end{array}$} \\
\hline 00249 & Prima & CHL & & $\mathrm{CV}$ & 1,1 & $\mathrm{a}$ & & & & & & \\
\hline 00257 & SAL 101 & AFS & & LM & 1,4 & $\mathrm{a}$ & $\mathrm{b}$ & & & & & \\
\hline 00140 & Bunheiro, Murtosa & PRT & Bunheiro, Murtosa & VT & 1,5 & $\mathrm{a}$ & $\mathrm{b}$ & c & & & & \\
\hline 00190 & Jambrina 1 & ESP & Serra da Gata, Salamanca & VT & 1,7 & $\mathrm{a}$ & $\mathrm{b}$ & c d & $\mathrm{e}$ & & & \\
\hline 00120 & Acc. $\mathrm{N}^{\circ} 435$ & ESP & & VT & 1,8 & $\mathrm{a}$ & $\mathrm{b}$ & $\mathrm{c} d$ & e & $\mathrm{f}$ & & \\
\hline 00263 & SWS St. 786 Blau & ALE & & LM & 1,8 & $\mathrm{a}$ & $\mathrm{b}$ & $\mathrm{c} d$ & & & & \\
\hline 00248 & Petkuser & ALE & & $\mathrm{CV}$ & 2,0 & $\mathrm{a}$ & $\mathrm{b}$ & c d & e & & & \\
\hline 00157 & Deisc. & PRT & & VT & 2,3 & $\mathrm{a}$ & $\mathrm{b}$ & $\mathrm{c} d$ & e & $\mathrm{f}$ & & \\
\hline 00232 & Moltolupa & ESP & & $\mathrm{CV}$ & 2,4 & & $\mathrm{~b}$ & c d & e & $\mathrm{f}$ & & \\
\hline 00216 & Lucky & FRA & & $\mathrm{CV}$ & 2,5 & a & $\mathrm{b}$ & $\mathrm{c} d$ & e & $\mathrm{f}$ & g 1 & $\mathrm{~h}$ \\
\hline 00033 & 26 & PRT & & VT & 2,6 & $\mathrm{a}$ & $\mathrm{b}$ & c d & e & $\mathrm{f}$ & g 1 & $\mathrm{~h}$ \\
\hline 00126 & Açores & PRT & Açores & VT & 2,6 & & & $\mathrm{c} d$ & $\mathrm{e}$ & f $s$ & $\mathrm{~g}$ & \\
\hline 00234 & Multitália & ITA & & $\mathrm{CV}$ & 2,6 & & $\mathrm{~b}$ & $\mathrm{c} d$ & $\mathrm{e}$ & $\mathrm{f} \xi \mathrm{g}-\mathrm{g}$ & $\mathrm{g}$ & \\
\hline 00238 & Neuland & ALE & & $\mathrm{CV}$ & 2,6 & & $\mathrm{~b}$ & $c d$ & $\mathrm{e}$ & $f \xi$ & g 1 & $\mathrm{~h}$ \\
\hline 00262 & SWS $186 / 89$ & ALE & & LM & 2,6 & $\mathrm{a}$ & $\mathrm{b}$ & c d & e & $\mathrm{f} \xi \mathrm{g} g \mathrm{~g}$ & g 1 & $\mathrm{~h}$ \\
\hline 00280 & Victoria & CHL & & $\mathrm{CV}$ & 2,6 & $\mathrm{a}$ & $\mathrm{b}$ & $\mathrm{c} d$ & e & $\mathrm{f}$ & g 1 & $\mathrm{~h}$ \\
\hline 00004 & 2 & PRT & & VT & 2,6 & $\mathrm{a}$ & $\mathrm{b}$ & $\mathrm{c} d$ & e & $\mathrm{f}$ & g 1 & $\mathrm{~h}$ \\
\hline 00136 & Bensafrim, Lagos & PRT & Bensafrim, Lagos & VT & 2,8 & $\mathrm{a}$ & $\mathrm{b}$ & $\mathrm{c} d$ & e & $\mathrm{f}$ & g & $\mathrm{h}$ \\
\hline 00230 & Misak & PRT & & $\mathrm{CV}$ & 2,8 & & & $\mathrm{c} d$ & $\mathrm{e}$ & f & g & $\mathrm{h}$ \\
\hline 00258 & SAL 106 & AFS & & LM & 2,9 & & $\mathrm{~b}$ & $\mathrm{c} d$ & $\mathrm{e}$ & f $s$ & g & $\mathrm{h}$ \\
\hline 00192 & Jambrina 3 & ESP & Serra da Gata, Salamanca & VT & 2,9 & & $\mathrm{~b}$ & $c d$ & $\mathrm{e}$ & f $g$ & g & $\mathrm{h}$ \\
\hline 00204 & L43-Mértola & PRT & Mértola & VT & 3,0 & & $\mathrm{~b}$ & $c d$ & e & $f_{\xi}$ & g & $\mathrm{h}$ \\
\hline 00208 & LA300 & FRA & & LM & 3,0 & & & $\mathrm{c} d$ & e & $f \xi$ & g & $\mathrm{h}$ \\
\hline 00224 & Madeira & PRT & Ilha da Madeira & VT & 3,0 & $\mathrm{a}$ & $\mathrm{b}$ & $\mathrm{c} d$ & e & f $\xi$ & $\mathrm{g}$ & $\mathrm{h}$ \\
\hline 00286 & $\mathrm{Xa} 100$ & FRA & & LM & 3,0 & $\mathrm{a}$ & $\mathrm{b}$ & $\mathrm{c} d$ & e & f & g & $\mathrm{h}$ \\
\hline 00137 & BL. $896-84$ & ALE & & LM & 3,1 & & & $\mathrm{~d}$ & e & $\mathrm{f}$ & g & $\mathrm{h}$ \\
\hline 00176 & Estoril & PRT & & $\mathrm{CV}$ & 3,1 & $\mathrm{a}$ & $\mathrm{b}$ & $\mathrm{c} d$ & $\mathrm{e}$ & $\mathrm{f}$ & g & $\mathrm{h}$ \\
\hline 00139 & Bolhos, Peniche & PRT & Bolhos, Peniche & VT & 3,2 & & $\mathrm{~b}$ & $c d$ & $\mathrm{e}$ & f & $\mathrm{g}$ & $\mathrm{h}$ \\
\hline 00113 & Aç 68 & PRT & Açores & VT & 3,2 & & & $\mathrm{c} d$ & $\mathrm{e}$ & $\mathrm{f}$ & $\mathrm{g}$ & $\mathrm{h}$ \\
\hline 00281 & Vladimir & RUS & & $\mathrm{CV}$ & 3,3 & & & & e & $\mathrm{f}$ & $\mathrm{g}$ & $\mathrm{h}$ \\
\hline 00283 & Weibit & ALE & & $\mathrm{CV}$ & 3,3 & & & d & e & $\mathrm{f}$ & g & $\mathrm{h}$ \\
\hline 00235 & Murtal & PRT & & $\mathrm{CV}$ & 3,4 & & & d & $\mathrm{e}$ & $\mathrm{f}$ & g & $\mathrm{h}$ \\
\hline 00115 & Aç 99 & PRT & Açores & VT & 3,5 & & & & e & $\mathrm{f}$ & g & $\mathrm{h}$ \\
\hline 00200 & Knehdener & ALE & & $\mathrm{CV}$ & 3,6 & & & & & $\mathrm{f}$ & g & $\mathrm{h}$ \\
\hline 00255 & S. Lourenço, Sabrosa & PRT & S. Lourenço, Sabrosa & VT & 3,6 & & & $\mathrm{c} d$ & e & $\mathrm{f}$ & g & $\mathrm{h}$ \\
\hline 00264 & SWS St. 786 Weiss & ALE & & LM & 3,6 & & & $\mathrm{~d}$ & $\mathrm{e}$ & $\mathrm{f}$ & $\mathrm{g}$ & $\mathrm{h}$ \\
\hline 00036 & 29 & PRT & & VT & 3,8 & & & & $\mathrm{e}$ & $\mathrm{f}$ & g & $\mathrm{h}$ \\
\hline 00009 & 5 & PRT & & VT & 3,9 & & & & $\mathrm{e}$ & $\mathrm{f}$ & $\mathrm{g}$ & $\mathrm{h}$ \\
\hline 00214 & LU115 & FRA & & LM & 4,0 & & & & & & g & $\mathrm{h}$ \\
\hline 00252 & Rio Maior & PRT & Rio Maior & VT & 4,0 & & & & & $\mathrm{f}$ & g & $\mathrm{h}$ \\
\hline 00229 & Minoti & ITA & & $\mathrm{CV}$ & 4,1 & & & & & & & $\mathrm{~h}$ \\
\hline 00288 & Kiev Mutant & UCR & & $\mathrm{CV}$ & 4,2 & & & & & & & $\mathrm{~h}$ \\
\hline 00250 & Primavera & CHL & & $\mathrm{CV}$ & 4,4 & & & & & & & $\mathrm{~h}$ \\
\hline 00184 & Hope & GBR & & $\mathrm{CV}$ & 4,4 & & & & & & & $\mathrm{~h}$ \\
\hline 00215 & Lublanc & FRA & & $\mathrm{CV}$ & 4,5 & & & & & & & $\mathrm{~h}$ \\
\hline 00212 & Lolita & CHL & & $\mathrm{CV}$ & 4,7 & & & & & & & $\mathrm{~h}$ \\
\hline 00254 & S. Brás de Alportel & PRT & S. Brás de Alportel & VT & 4,8 & & & & & & & $\mathrm{~h}$ \\
\hline 00225 & Madeira 1 & PRT & Ilha da Madeira & VT & 4,8 & & & & & & & $\mathrm{~h}$ \\
\hline 00125 & Acc. $\mathrm{N}^{\circ} 774$ & GRE & & VT & 4,9 & & & & & & & $\mathrm{~h}$ \\
\hline 00168 & EAN 856 & PRT & Marmelete, Monchique & VT & 5,0 & & & & & & & $\mathrm{~h}$ \\
\hline 00203 & L34-Torres Vedras & PRT & Torres Vedras & VT & 5,0 & & & & & & & $\mathrm{~h}$ \\
\hline
\end{tabular}

aPaís: AFS, África do Sul; ALE, Alemanha; CHL, Chile; ESP, Espanha; FRA, França; GBR, Grã Bretanha; GRE, Grécia; ITA, Itália; PRT, Portugal; RUS, Rússia; UCR, Ucrânia; bTipo de germoplasma: CV, cultivar; LM, linha de melhorador; VT, variedade tradicional;

'Acessos com uma ou mais letras em comum não diferem em termos estatísticos para um nível de significância de 95\%.

de Bunheiro, Murtosa (acesso 00140). De entre os acessos classificados como mais suscetíveis à antracnose surgem várias cultivares modernas (como, por exemplo, 00215 'Lublanc' ou 00288
'Kiev Mutant') mas também diversas variedades tradicionais portuguesas oriundas de regiões tão distintas como Monchique, S. Brás de Alportel, Torres Vedras ou ilha da Madeira. 
Em $L$. angustifolius verifica-se que os valores médios de severidade da doença oscilaram entre 0,0 e 5,0, com uma média geral de 3,6. Procedendo a ANOVA e a testes de comparação de médias, verifica-se a existência de diferenças significativas entre os acessos em estudo no que se refere à resistência à antracnose (Quadro 7).
Dos 46 acessos de L. angustifolius estudados, seis foram classificados como resistentes (valores médios de severidade de 0-2) e os restantes 40 como suscetíveis (valores médios de severidade de 3-5), ainda que alguns acessos surgindo nos dois grupos não apresentem diferenças estatisticamente significativas. Todos os acessos classificados como resistentes correspondem a germoplasma espontâneo português. Destes, quatro foram

Quadro 7 - Médias e grupos homogéneos (teste de Tukey, 95\%) para a severidade da infeção causada por Colletotrichum lupini (isolado 96A4) em acessos de Lupinus angustifolius

\begin{tabular}{|c|c|c|c|c|c|c|c|c|c|c|}
\hline Ref. & Nome & País ${ }^{\mathrm{a}}$ & Local & Tipo $^{b}$ & Média & \multicolumn{5}{|c|}{$\begin{array}{c}\text { Gr. } \\
\text { Homogéneos }^{c}\end{array}$} \\
\hline 10039 & Alt97-16 & $\overline{P R T}$ & Monte Paleiros, Portalegre & GE & 0,0 & $\mathrm{a}$ & & & & \\
\hline 10042 & Alt97-19 & PRT & Monte Paleiros, Portalegre & GE & 1,3 & $\mathrm{~b}$ & & & & \\
\hline 10037 & Alt97-14 & PRT & Monte Paleiros, Portalegre & $\mathrm{GE}$ & 2,0 & $\mathrm{~b}$ & $\mathrm{c}$ & & & \\
\hline 10121 & BI97-25 & PRT & Pinhel & GE & 2,0 & $\mathrm{~b}$ & $\mathrm{c}$ & & & \\
\hline 10145 & EAN 954 & PRT & Hortas, Portalegre & GE & 2,0 & $\mathrm{~b}$ & $\mathrm{c}$ & & & \\
\hline 10128 & BI97-5 & PRT & Castelo Branco & GE & 2,3 & & c d & & & \\
\hline 10146 & EAN 958 & PRT & Hortas, Portalegre & GE & 2,5 & & c d & $\mathrm{e}$ & & \\
\hline 10116 & BI97-12 & PRT & Castelo Branco & GE & 2,8 & & c d & $\mathrm{e}$ & $\mathrm{f}$ & \\
\hline 10143 & EAN 948 & PRT & Degolados (prox.), Arronches & GE & 2,8 & & c d & $\mathrm{e}$ & $\mathrm{f}$ & \\
\hline 10050 & Alt97-26 & PRT & Sta. Eulália, Elvas & GE & 3,0 & & c d & $\mathrm{e}$ & & \\
\hline 10163 & Kalya & AUS & & $\mathrm{CV}$ & 3,2 & & $\mathrm{~d}$ & $\mathrm{e}$ & $\mathrm{f}$ & \\
\hline 10195 & Tallerack & AUS & & $\mathrm{CV}$ & 3,3 & & $\mathrm{~d}$ & $\mathrm{e}$ & $f$ & \\
\hline 10001 & 3075 & ESP & & LM & 3,3 & & & $\mathrm{e}$ & $\mathrm{f}$ & \\
\hline 10122 & BI97-27 & PRT & Cast. Rodrigo, Fig. C. Rodrigo & GE & 3,3 & & $\mathrm{~d}$ & e & $f g$ & $g$ \\
\hline 10123 & BI97-28 & PRT & Cast. Rodrigo, Fig. C. Rodrigo & GE & 3,3 & & $\mathrm{~d}$ & $\mathrm{e}$ & $f \mathrm{~g}$ & g \\
\hline 10127 & BI97-4 & PRT & Castelo Branco & GE & 3,3 & & & $\mathrm{e}$ & $\mathrm{f}$ & \\
\hline 10199 & Wonga & AUS & & $\mathrm{CV}$ & 3,4 & & & $\mathrm{e}$ & $\mathrm{f}$ & \\
\hline 10049 & Alt97-25 & PRT & Crato & GE & 3,5 & & & $\mathrm{e}$ & $\mathrm{f}$ & \\
\hline 10076 & Alt97-5 & PRT & S. Salvador, Marvão & GE & 3,5 & & & $\mathrm{e}$ & $\mathrm{f}$ & \\
\hline 10092 & Alt97-64 & PRT & Juromenha (prox.), Elvas & GE & 3,5 & & & e & $f$ & \\
\hline 10162 & Jambrina 3 & ESP & & LM & 3,5 & & & $\mathrm{e}$ & $\mathrm{f}$ & \\
\hline 10144 & EAN 952 & PRT & Alegrete, Portalegre & GE & 3,5 & & & e & $\mathrm{f}$ & \\
\hline 10166 & Marri & AUS & & $\mathrm{CV}$ & 3,5 & & & e & $f g$ & $g$ \\
\hline 10147 & EAN 965 & PRT & Alvarrões, Marvão & GE & 3,6 & & & $\mathrm{e}$ & $f \mathrm{~g}$ & g \\
\hline 10112 & Belara & & & $\mathrm{CV}$ & 3,7 & & & $\mathrm{e}$ & $f g$ & g \\
\hline 10197 & Uniharvest & AUS & & $\mathrm{CV}$ & 3,8 & & & $\mathrm{e}$ & $f \quad g$ & g \\
\hline 10098 & Alt97-70 & PRT & Courelas da Toura, Évora & GE & 3,8 & & & & $f g$ & \\
\hline 10099 & Alt97-71 & PRT & Courelas da Toura, Évora & GE & 3,8 & & & & $f \quad g$ & $\mathrm{~g}$ \\
\hline 10169 & Moredou & AUS & & $\mathrm{CV}$ & 3,8 & & & & $f g$ & $\mathrm{~g}$ \\
\hline 10063 & Alt97-38 & PRT & Arronches & GE & 4,0 & & & $\mathrm{e}$ & $f \quad g$ & $\mathrm{~g}$ \\
\hline 10102 & Alt $97-74$ & PRT & Courelas da Toura, Évora & GE & 4,0 & & & $\mathrm{e}$ & $f g$ & g \\
\hline 10124 & BI97-29 & PRT & Ribeira da Pega, Pinhel & GE & 4,0 & & & $\mathrm{e}$ & $f g$ & g \\
\hline 10157 & Gungurru & AUS & & $\mathrm{CV}$ & 4,1 & & & $\mathrm{e}$ & $f g$ & g \\
\hline 10196 & Unicrop & AUS & & $\mathrm{CV}$ & 4,2 & & & e & $f \quad g$ & $\mathrm{~h}$ \\
\hline 10052 & Alt97-28 & PRT & Arronches & GE & 4,3 & & & & $f g$ & $\mathrm{~g} h$ \\
\hline 10081 & Alt97-54 & PRT & Sta. Eulália, Elvas & GE & 4,3 & & & & $\mathrm{~g}$ & $\mathrm{~g}$ \\
\hline 10082 & Alt97-55 & PRT & Sta. Eulália, Elvas & GE & 4,3 & & & & & g \\
\hline 10086 & Alt97-59 & PRT & Sta. Eulália, Elvas & GE & 4,3 & & & & $\mathrm{~g}$ & $\mathrm{~g}$ \\
\hline 10101 & Alt $97-73$ & PRT & Courelas da Toura, Évora & GE & 4,3 & & & & $\mathrm{~g}$ & g \\
\hline 10158 & Illyarrie & AUS & & $\mathrm{CV}$ & 4,4 & & & & & $\mathrm{~g} h$ \\
\hline 10003 & 3084 & ESP & & LM & 4,5 & & & & & g h \\
\hline 10131 & Danja & AUS & & $\mathrm{CV}$ & 4,6 & & & & $\mathrm{~g}$ & $\mathrm{~h}$ \\
\hline 10180 & Rancher & EUA & & $\mathrm{CV}$ & 4,8 & & & & & $\mathrm{~h}$ \\
\hline 10002 & 3082 & ESP & & LM & 5,0 & & & & & $\mathrm{~h}$ \\
\hline 10014 & A 80 & ITA & & LM & 5,0 & & & & & $\mathrm{~h}$ \\
\hline 10160 & Jambrina 1 & ESP & & LM & 5,0 & & & & & $\mathrm{~h}$ \\
\hline 10161 & Jambrina 2 & ESP & & LM & 5,0 & & & & & $\mathrm{~h}$ \\
\hline
\end{tabular}

aPaís: AUS, Austrália; ESP, Espanha; EUA; Estados Unidos da América; ITA, Itália; PRT, Portugal;

'Tipo de germoplasma: CV, cultivar; GE, germoplasma espontâneo; LM, linha de melhorador;

'Acessos com uma ou mais letras em comum não diferem em termos estatísticos para um nível de significância de $95 \%$. 
obtidos no concelho de Portalegre (acessos 10037, 10039, 10042 e 10145), um no de Castelo Branco (acesso 10128) e outro no de Pinhel (acesso 10121). As cultivares modernas e linhas de melhorador analisadas mostraram-se suscetíveis à doença. Também diversas amostras de germoplasma espontâneo se mostraram suscetíveis. As linhas semi-domesticadas, morfologicamente intermédias entre as amostras selvagens e as cultivares modernas, comportaram-se também como suscetíveis.

Em L. luteus, os valores médios para a severidade da infeção causada por C. lupini variaram entre um mínimo de 1,0 e um máximo de 4,8, com uma média geral de 3,2 . Procedendo a ANOVA e a testes de comparação de médias verifica-se a existência de diferenças significativas entre os acessos em estudo no que se refere à resistência à antracnose (Quadro 8).

Dos 19 acessos de L. luteus estudados, oito foram classificados como resistentes e 11 como suscetíveis. Entre os acessos classificados como resistentes pontuam três amostras de germoplasma espontâneo português, oriundas de Alcoutim, Aljezur e de Castelo Branco (respetivamente acessos 20040, 20068 e 20063), assim como diversas cultivares, como 'Amulet' (20031), 'Aurea' (20036), 'Sulfa' (20118), 'Topaz' (20123) e 'Weiko II' (20130).
Entre os acessos classificados como suscetíveis surgem, de igual modo, amostras de germoplasma espontâneo português e cultivares de diversas origens.

Em L. mutabilis todos os dez acessos inoculados foram classificados como suscetíveis, variando a severidade média das infeções entre 3,7 e 5,0, com uma média geral de 4,7 , sendo reduzidas as diferenças encontradas (Quadro 9).

Procedeu-se ao estudo da distribuição dos diversos acessos de cada espécie em função da classificação que lhes foi atribuída no que se refere à severidade de infeção com C. lupini. Tal análise permite comparar as quatro espécies em estudo, tal como esquematizado na Figura 3.

Verifica-se que $90 \%$ dos acessos de L. mutabilis se distribuem por valores de severidade superiores a quatro, mostrando os acessos desta espécie claramente como mais suscetíveis que os restantes. De entre as restantes espécies é de realçar a importante proporção de acessos de L. luteus com valores abaixo de 2,5, o facto de grande parte dos acessos de L. albus se situar entre valores de dois e quatro e ainda o facto de ser a espécie $L$. angustifolius aquela que regista acessos com os mais baixos valores médios de severidade de infeção.

Quadro 8 - Médias e grupos homogéneos (teste de Tukey, 95\%) para a severidade da infeção causada por Colletotrichum lupini (isolado 96A4) em acessos de Lupinus luteus

\begin{tabular}{|c|c|c|c|c|c|c|c|c|c|}
\hline Ref. & Nome & País $^{\mathrm{a}}$ & Local & Tipo $^{b}$ & Média & $\mathbf{G r}$ & . & Ion & n. ${ }^{a}$ \\
\hline 20031 & Amulet & & & $\mathrm{CV}$ & 1,0 & $\bar{a}$ & & & \\
\hline 20130 & Weiko II & ALE & & $\mathrm{CV}$ & 1,3 & $\mathrm{a}$ & $\mathrm{b}$ & & \\
\hline 20118 & Sulfa & ALE & & $\mathrm{CV}$ & 1,5 & $\mathrm{a}$ & $\mathrm{b}$ & & \\
\hline 20068 & EAN 853 & PRT & Eirinhas, Aljezur & GE & 1,6 & $\mathrm{a}$ & $\mathrm{b}$ & & \\
\hline 20040 & BI97-10 & PRT & Castelo Branco & GE & 2,0 & $\mathrm{a}$ & $\mathrm{b}$ & $\mathrm{c}$ & \\
\hline 20036 & Aurea & $\mathrm{CHL}$ & & $\mathrm{CV}$ & 2,2 & $\mathrm{a}$ & $\mathrm{b}$ & $\mathrm{c}$ & \\
\hline 20123 & Topaz & POL & & $\mathrm{CV}$ & 2,2 & $\mathrm{a}$ & $\mathrm{b}$ & $\mathrm{c}$ & \\
\hline 20063 & EAN 1028 & PRT & Clarimes, Alcoutim & GE & 2,3 & $\mathrm{a}$ & $\mathrm{b}$ & $\mathrm{c}$ & \\
\hline 20027 & Alt97-9 & PRT & Castelo de Vide & GE & 3,1 & & $\mathrm{~b}$ & $\mathrm{c}$ & $\mathrm{d}$ \\
\hline 20059 & EAN 1010 & PRT & Meia Viana, Monchique & GE & 3,6 & & & $\mathrm{c}$ & $\mathrm{d}$ \\
\hline 20072 & EAN 895 & PRT & Ameixial, Loulé & GE & 3,7 & & & $\mathrm{c}$ & $\mathrm{d}$ \\
\hline 20077 & Gwlzower ST-R-M & ALE & & $\mathrm{CV}$ & 3,9 & & & $\mathrm{c}$ & d \\
\hline 20134 & Wodjil & AUS & & $\mathrm{CV}$ & 4,1 & & & $\mathrm{c}$ & d \\
\hline 20103 & Ratucki & POL & & $\mathrm{CV}$ & 4,2 & & & & $\mathrm{~d}$ \\
\hline 20064 & EAN 839 & PRT & Sonega, Santiago do Cacém & GE & 4,6 & & & & $\mathrm{~d}$ \\
\hline 20085 & Lila & ALE & & $\mathrm{CV}$ & 4,7 & & & & $\mathrm{~d}$ \\
\hline 20122 & Tomik & POL & & $\mathrm{CV}$ & 4,7 & & & & $\mathrm{~d}$ \\
\hline 20034 & Atus & & & $\mathrm{CV}$ & 4,8 & & & & $\mathrm{~d}$ \\
\hline 20073 & EAN 898 & PRT & Azinhal, Loulé & GE & 4,8 & & & & $\mathrm{~d}$ \\
\hline
\end{tabular}

aPaís: ALE, Alemanha; CHL, Chile; POL, Polónia; PRT, Portugal;

'Tipo de germoplasma: CV, cultivar; GE, germoplasma espontâneo;

'Acessos com uma ou mais letras em comum não diferem em termos estatísticos para um nível de significância de $95 \%$. 
Quadro 9- Médias e grupos homogéneos (teste de Tukey, 95\%) para a severidade da infeção causada por Colletotrichum lupini (isolado 96A4) em acessos de Lupinus mutabilis

\begin{tabular}{|c|c|c|c|c|c|c|}
\hline$\overline{A c e s s o}$ & Nome & País ${ }^{a}$ & Tipo $^{b}$ & Média & $\overline{G . I}$ & $\overline{\text {H. }^{c}}$ \\
\hline 40010 & LM13 & \multirow{10}{*}{ CHL } & $\mathrm{LM}$ & 3,7 & $\bar{a}$ & \\
\hline 40016 & LM34 & & LM & 4,4 & $\mathrm{a}$ & $\mathrm{b}$ \\
\hline 40012 & LM231 & & LM & 4,6 & $\mathrm{a}$ & $\mathrm{b}$ \\
\hline 40013 & LM268 & & LM & 4,7 & & $\mathrm{~b}$ \\
\hline 40683 & XM5 & & LM & 4,9 & & $\mathrm{~b}$ \\
\hline 40008 & Inti & & LM & 5,0 & & $\mathrm{~b}$ \\
\hline 40014 & LM27 & & LM & 5,0 & & $\mathrm{~b}$ \\
\hline 40666 & P20993 & & LM & 5,0 & & $\mathrm{~b}$ \\
\hline 40668 & Potosi & & LM & 5,0 & & $\mathrm{~b}$ \\
\hline 40669 & Prt79 & & LM & 5,0 & & $\mathrm{~b}$ \\
\hline
\end{tabular}

aPaís: CHL, Chile;

'Tipo de germoplasma: LM, linha de melhorador;

'G.H., Grupos homogéneos: acessos com uma ou mais letras em comum não diferem em termos estatísticos para um nível de significância de $95 \%$.

\section{Ensaio de campo}

No ensaio de campo foram comparados sete acessos contrastantes de L. albus, tanto sujeitos a condições de infeção como a condições pouco favoráveis à infeção. Para tal, foram analisados os diversos componentes de produção.

Numa apreciação qualitativa geral do ensaio, foi possível observar, na modalidade inoculada com o fungo, diversos sintomas típicos de antracnose, tais como lesões necróticas nos caules e nas vagens, assim como o típico enrolamento de caules e pecíolos. Tais sintomas foram também observáveis na modalidade sem inoculação mas mantida em condições de humidade semelhantes às da modalidade inoculada (modalidade 2), o que se deverá à dispersão de inóculo a partir da modalidade inoculada com o fungo, apesar da existência de bordadura.

Analisando o peso de sementes produzido por planta, verifica-se que o acesso 00208 (linha de melhorador francesa LA300) apresentou os valores mais baixos para esta característica em qualquer das modalidades ensaiadas. Neste acesso, assim como para 00140 (variedade tradicional de Murtosa), 00190 (variedade tradicional de Salamanca), 00252 (variedade tradicional de Rio Maior) e 00280 (cultivar chilena 'Victoria'), verificou-se a inexistência de diferenças significativas entre as três modalidades testadas. Pelo contrário, para os acessos 00126 (variedade tradicional dos Açores) e 00230 (cultivar portuguesa 'Misak'),

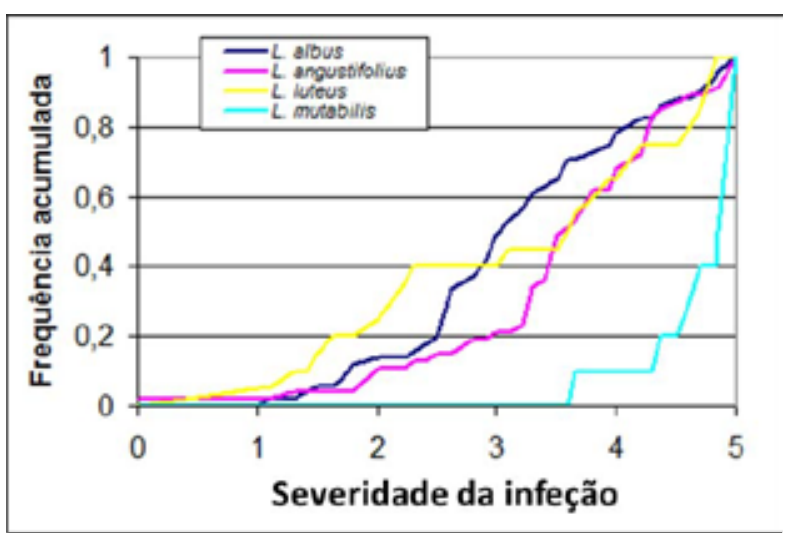

Figura 3 - Frequência acumulada do número de acessos para cada espécie de Lupinus em função da severidade da infeção por Colletotrichum lupini (isolado 96A4) em estufa.

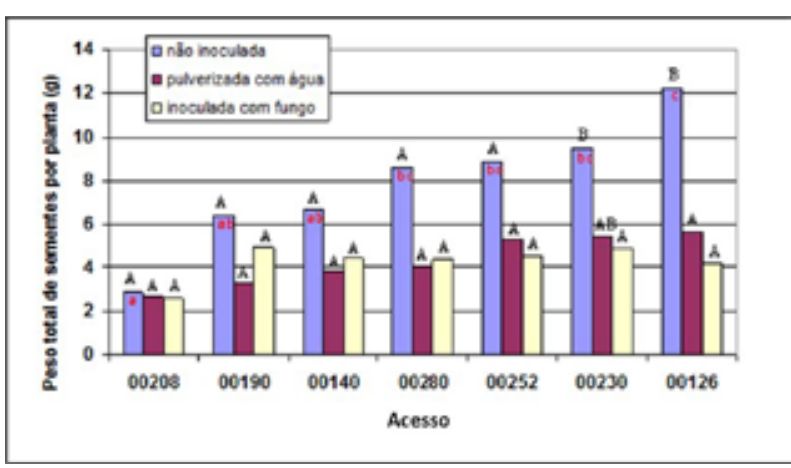

Figura 4 - Peso de sementes obtido por planta (g) em sete acessos de Lupinus albus sujeitas a inoculação com Colletotrichum lupini (isolado 2) sob condições favoráveis à infeção (“inoculada com o fungo"), ou alternativamente sujeitas a condições semelhantes mas sem inoculação ("pulverizada com água") ou sem inoculação nem condições de humidade ("não inoculada"); para cada acesso, barras com letras maiúsculas comuns não são significativamente diferentes (teste de Tukey a $95 \%$ de confiança); para a modalidade não inoculada, e comparando os diferentes acessos, barras com letras minúsculas vermelhas comuns não são significativamente diferentes (teste de Tukey a 95\% de confiança).

foi possível verificar a existência de diferenças significativas entre a modalidade mantida em condições normais de campo, modalidade 3, e a modalidade inoculada com o fungo, modalidade 1 (Figura 4). Comparando os sete acessos, verificase a existência de diferenças significativas no seio da modalidade não inoculada (Figura 4), não se verificando no entanto tais diferenças quando se comparam os acessos para qualquer uma das restantes duas modalidades. 


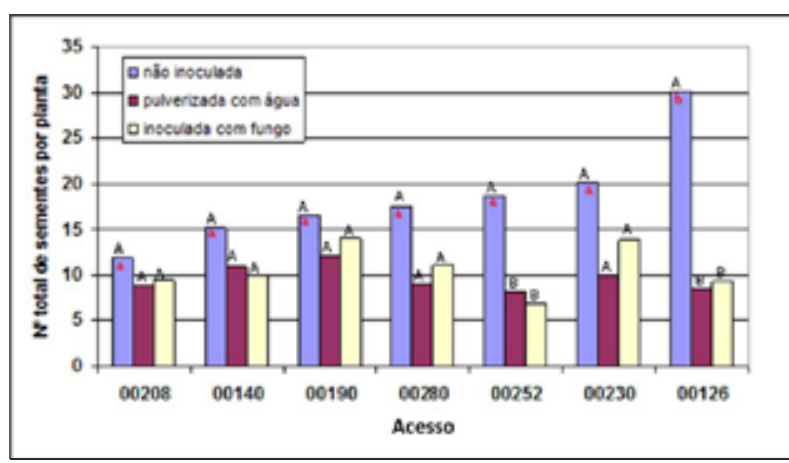

Figura 5 - Número de sementes obtido por planta em sete acessos de Lupinus albus sujeitas a inoculação com Colletotrichum lupini (isolado 2) sob condições de humidade alta, ou alternativamente sujeitas a condições semelhantes mas sem inoculação ou sem inoculação nem condições de humidade; para cada acesso, barras com letras maiúsculas comuns não são significativamente diferentes (teste de Tukey a $95 \%$ de confiança); para a modalidade não inoculada, e comparando os diferentes acessos, barras com letras minúsculas vermelhas comuns não são significativamente diferentes (teste de Tukey a 95\% de confiança).

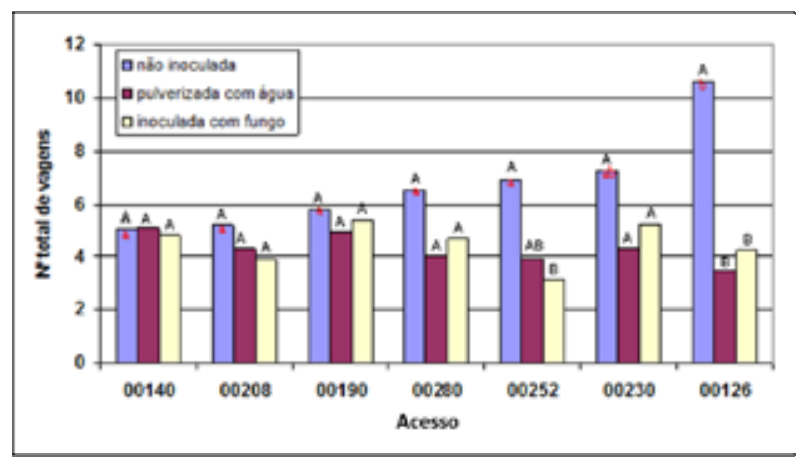

Figura 6 - Número de vagens obtido por planta em sete acessos de Lupinus albus sujeitas a inoculação com Colletotrichum lupini (isolado 2) sob condições de humidade alta, ou alternativamente sujeitas a condições semelhantes mas sem inoculação ou sem inoculação nem condições de humidade; para cada acesso, barras com letras maiúsculas comuns não são significativamente diferentes (teste de Tukey a $95 \%$ de confiança); para a modalidade não inoculada, e comparando os diferentes acessos, barras com letras minúsculas vermelhas comunsnão são significativamente diferentes (teste de Tukey a $95 \%$ de confiança).

As diferenças verificadas entre plantas inoculadas e não inoculadas representaram uma quebra de produção oscilando entre um mínimo de 3,6\% (acesso 00208) e um máximo de $64,6 \%$ (acesso 00126). Tais quebras são sobretudo devidas a diferenças encontradas nas sementes produzidas

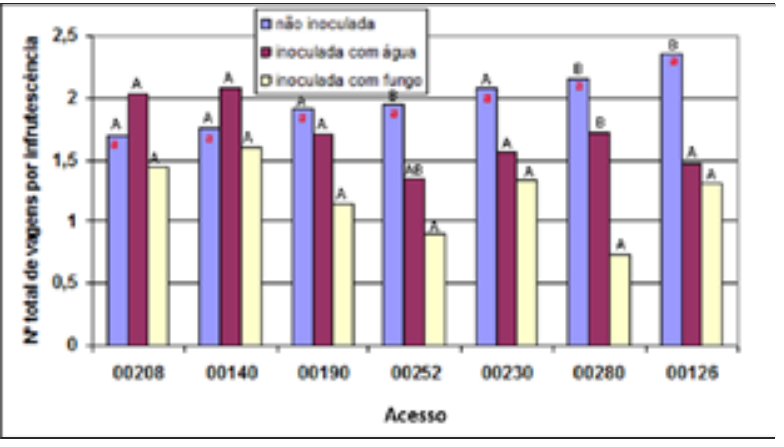

Figura 7 - Número total de vagens por infrutescência obtido por planta em sete acessos de Lupinus albus sujeitas a inoculação com Colletotrichum lupini (isolado 2) sob condições de humidade alta, ou alternativamente sujeitas a condições semelhantes mas sem inoculação ou sem inoculação nem condições de humidade; para cada acesso, barras com letras maiúsculas comuns não são significativamente diferentes (teste de Tukey a 95\% de confiança); para a modalidade não inoculada, não foram registadas diferenças significativas (teste de Tukey a 95\% de confiança) comparando os diferentes acessos (letras minúsculas vermelhas).

nas ramificações primárias, já que a produção de semente nas vagens do caule principal não apresenta diferenças significativas entre as três modalidades ensaiadas.

Resultados semelhantes aos verificados com a análise do peso de sementes foram encontrados para o número de sementes e para o número de vagens, mas com menos modalidades apresentando diferenças significativas (Figuras $5 \mathrm{e}$ 6). Já a análise do número total de infrutescências não revela a existência de diferenças significativas entre modalidades para qualquer acesso.

Para os acessos 00126, 00252 e 00280 verificase a existência de diferenças significativas para o número de vagens por infrutescência entre a modalidade inoculada com o fungo e a modalidade mantida em condições normais, sendo tais valores superiores na segunda modalidade referida (Figura 7). Tais diferenças já não se verificam a nível do número de sementes por vagem. De igual forma, as diferentes modalidades de inoculação não originaram diferenças para o peso de mil grãos.

Assim, a nível dos componentes de produção [considerando o esquema clássico dos componentes da produção, em que a produção final duma planta 
(em gramas de semente por planta) de L. albus resulta do produto dos seguintes componentes: $\mathrm{n}^{\mathrm{o}}$ de infrutescências $\times \mathrm{n}^{\mathrm{o}}$ vagens/infrutescência $\times$ $\mathrm{n}^{\mathrm{o}}$ sementes/vagem $\times$ peso de mil grãos], a maior produção de semente obtida na modalidade não inoculada, para a generalidade dos acessos, decorre sobretudo dos maiores valores verificados para o número de vagens por infrutescência, não se verificando diferenças significativas quer a nível da dimensão das sementes (traduzido pelo peso de mil grãos) quer no número de sementes por vagem, nem mesmo no número total de infrutescências. Apesar dos sintomas de antracnose serem mais visíveis a nível dos caules, a infeção e abcisão de flores, sobretudo nas ramificações primárias e secundárias, é um importante componente da redução da produção ocasionada pela infeção com o fungo. Tais infeções, afetando as flores, justificam a redução verificada no número de vagens por infrutescência. Infeções nos caules justificariam reduções no número de infrutescências, que não ocorreram de forma significativa, apesar de terem surgido abundantes infeções nos caules. De igual forma, infeções nas vagens justificariam reduções no número de sementes por vagem, que também não ocorreram de forma significativa. Infeções nas sementes justificariam reduções no peso de mil grãos, que do mesmo modo não foram verificadas, ainda que o maior determinismo genético que recai sobre esta característica tornasse este resultado previsível.

\section{DISCUSSÃO}

\section{Resistência comparativa de espécies e acessos}

Os ensaios em estufa mostram a espécie $L$. mutabilis como claramente mais suscetível que as restantes. Ao contrário do que seria de esperar, a espécie $L$. albus não se revelou mais suscetível que L. angustifolius, tendo no entanto mostrado menor variabilidade que aquela no que se refere à resposta diferenciada à antracnose dos diversos acessos em estudo.

Foi possível identificar acessos de L. albus, $L$. angustifolius e L. luteus exibindo baixos níveis de suscetibilidade à antracnose, permitindo a sua classificação como resistentes. De entre o germoplasma português, merece destaque uma
variedadetradicionaldeL.albus oriunda deMurtosa, várias amostras de germoplasma selvagem de $L$. angustifolius de Arronches e Portalegre e alguns acessos de L. luteus do Algarve e Beira Baixa. É de realçar o facto de, em $L$. albus e em L. luteus, algumas cultivares de diversas origens terem sido consideradas como resistentes, confirmando-se a classificação de resistente atribuída anteriormente à cultivar chilena 'Prima' (Galdames e Peñaloza, 1999). Já em L. angustifolius, nenhuma das cultivares modernas analisadas pode ser considerada como resistente, nem mesmo a cultivar 'Wonga', tida como uma das cultivares mais resistentes de $L$. angustifolius (Cowling et al., 2000). Verifica-se que os acessos de L. angustifolius mais resistentes são os que apresentam maior desenvolvimento vegetativo (Talhinhas et al., 2006). Neste grupo incluem-se tanto linhas totalmente selvagens, apresentando nomeadamente tegumento impermeável e vagens deiscentes, como linhas com diversos graus de domesticação (sempre, no mínimo, apresentando tegumento permeável e vagens indeiscentes), provenientes da África do Sul e da Alemanha, de utilização para forragem e sideração (e assim de grande desenvolvimento vegetativo).

Comparando os resultados obtidos com resultados referentes aos padrões de diversidade para os mesmos acessos de Lupinus spp. (Talhinhas et al., 2003, 2006), é possível constatar uma correspondência entre a maior variabilidade encontrada entre acessos de L. angustifolius no que se refere à resistência à antracnose e a maior variabilidade encontrada entre acessos desta espécie no que se refere à diversidade genética geral, nomeadamente quando estimada por marcadores moleculares. Por comparação, os acessos de L. albus, e sobretudo de L. mutabilis (Talhinhas, 1994), mostram menor variabilidade no que se refere à resistência à antracnose e no âmbito dos padrões de diversidade genética estudados com ferramentas moleculares.

\section{Componentes da produção}

O ensaio de campo avaliando os componentes da produçãodediversos acessosem respostaà presença ou não do fungo, e em condições ambientais favoráveis ou desfavoráveis à doença, mostrou a existência de quebras de produção significativas nos acessos que se mostram mais produtivos em condições desfavoráveis à doença. Em condições 
favoráveis à infeção (com ou sem inoculação com o fungo) verificou-se uma importante redução da produtividade das plantas sobretudo ao nível dos ramos primários, com grande parte das flores ou vagens abortadas, exibindo sintomas de antracnose. Não se verificaram diferenças significativas ao nível da produção de semente dos sete acessos estudados quando mantidos em condições favoráveis à doença.

Ao nível dos componentes de produção, verifica-se que são os acessos que exibem maior desenvolvimento vegetativo (Talhinhas et al., 2003, 2006) que exibem níveis significativamente inferiores para o número de vagens por infrutescência quando se comparam as modalidades inoculada e não inoculada. Para os restantes componentes da produção, são reduzidas as diferenças encontradas entre os diversos acessos e as diversas modalidades de inoculação. Apesar das necroses nos caules e vagens serem os sintomas mais evidentes de antracnose, o aborto floral causado pelo fungo parece ser o mais importante componente da redução da produção nos acessos infetados.

\section{CONCLUSÕES}

Para qualquer das espécies onde foi encontrada variabilidade na resistência à antracnose ( $L$. albus, $L$. angustifolius e L. luteus), a realização de cruzamentos entre linhas exibindo comportamentos extremos poderá permitir esclarecer os mecanismos genéticos que presidem a estas resistências. As linhas consideradas mais resistentes poderão ser integradas em programas de melhoramento visando a incorporação de maiores níveis de resistência em cultivares. Estudos recentes conduzidos na Austrália permitiram a identificação de resistência em variedades tradicionais etíopes de L. albus (Adhikari et al., 2009, 2013).

Apesar dos fungos do género Colletotrichum, e dos fungos do complexo de espécies $C$. acutatum em particular, serem considerados polífagos, o agente causal da antracnose de Lupinus, Colletotrichum lupini, constitui um grupo especializado, bem definido e homogéneo (Talhinhas et al., 2016). Esta especialização (traduzida aliás num quadro sintomatológico extremamente invulgar no género), juntamente com a sua reduzida variabilidade genética e recente dispersão mundial, sugere uma possível origem recente para este fungo, porventura centrada na América do Sul, de acordo com dados filogeográficos (Talhinhas et al., dados não publicados). Por contraste com a grande diversidade genética dos hospedeiros, traduzida também em diversidade genética no que respeita à resistência à doença, é notável o sucesso deste agente patogénico, tornando este patossistema num caso de estudo no âmbito da fitopatologia (Talhinhas et al., 2016).

\section{REFERÊNCIAS BIBLIOGRÁFICAS}

Adhikari, K.N.; Buirchell, B.J.; Thomas, G.J.; Sweetingham, M.W. e Yang, H. (2009) - Identification of anthracnose resistance in Lupinus albus $\mathrm{L}$. and its transfer from landraces to modern cultivars. Crop and Pasture Science, vol. 60, n. 5, p. 472-479. http://dx.doi.org/10.1071/CP08092

Adhikari, K.N.; Thomas, G.; Diepeveen, D. e Trethowan, R. (2013) - Overcoming the barriers of combining early flowering and anthracnose resistance in white lupin (Lupinus albus L.) for the Northern Agricultural Region of Western Australia. Crop and Pasture Science, vol. 64, n. 9, p. 914-921. http://dx.doi.org/10.1071/CP13249

Agrios, G. (1997) - Plant Pathology. 4th Edition. Academic Press. San Diego, CA, U.S.A.

Baier, A.C. e Linhares, A.G. (1991) - Breeding for anthracnose resistance in lupines in southern Brazil. In: (von Baer, D., ed.) - Proceedings of the 6th International Lupin Conference, Temuco-Pucón, 25-30 November 1990. pp. 363-365. Asociación Chilena del Lupino. Temuco, Chile.

Baroncelli, R.; Zapparata, A.; Sarrocco, S.; Sukno, S.A.; Lane, C.R.; Thon, M.R.; Vannacci, G.; Holub, E. e Sreenivasaprasad, S. (2015) - Molecular diversity of anthracnose pathogen populations associated with UK strawberry production suggests multiple introductions of three different Colletotrichum species. PLoS One, vol. 10, art. e0129140. http://dx.doi.org/10.1371/journal.pone.0129140 
Bennett, J.C.; Diggle, A.; Evans, F. e Renton, M. (2013) - Assessing eradication strategies for rain-splashed and wind-dispersed crop diseases. Pest Management Science, vol. 69, n. 8, p. 955-963. http://dx.doi.org/10.1002/ps.3459

Bhaskara Reddy, M.V.; Atlin, G. e Paulitz, T.C. (1996) - Response of white lupine cultivars to Phoma sp. and Colletotrichum gloeosporioides. Canadian Journal of Plant Pathology, vol. 18, n. 3, p. 272-278. http://dx.doi.org/10.1080/07060669609500624

Cowling, W.A.; Buirchell, B.J.; Frencel, I.; Koch, S.; Neves-Martins, J.M.; Römer, P.; Sweetingham, M.W.; Talhinhas, P.; van Santen, E.; von Baer, E. e Yang, H. (2000) - International evaluation of resistance to anthracnose in lupin. In: (van Santen, E.; Wink, M.; Weissmann, S. e Römer, P., eds.) - Lupin, an ancient crop for the new millennium. Proceedings of the 9th International Lupin Conference, 20-24 June 1999, Klink/ Müritz. pp. 16-22. International Lupin Association. Canterbury.

Cowling, W.A.; Buirchell, B.J. e Tapia, M.E. (1998) - Lupin. Lupinus L. Promoting the conservation and use of underutilized and neglected crops. 23. IPGRI. Rome, Italy.

Damm, U.; Cannon P.F.; Woudenberg J.H. e Crous P.W. (2012) - The Colletotrichum acutatum species complex. Studies in Mycology, vol. 73, p. 37-113. http://dx.doi.org/10.3114/sim0010

Decker, P. (1947) - Anthracnose of blue lupin is seed-borne. Plant Disease Reporter, vol. 31, p. 270-271.

Dick, M.A. (1994) - Blight of Lupinus arboreus in New Zealand. New Zealand Journal of Forestry Science, vol. 24, n. 1, p. 51-68.

Falconí, C.E.; Visser, R.G.F. e van Heusden, A.W. (2013) - Phenotypic, molecular, and pathological characterization of Colletotrichum acutatum associated with andean lupine and tamarillo in the Ecuadorian Andes. Plant Disease, vol. 97, n. 6, p. 819-827. http://dx.doi.org/10.1094/ PDIS-02-12-0175-RE

Forbes, I. \& Wells, H. D. (1961) - Inheritance of resistance to anthracnose in blue lupines, Lupinus angustifolius L. Crop Science, vol. 1, p. 139-141.

Frey, F.; Gassen, D.N. e Baier, A.C. (1993) - Doenças e insetos associados à cultura do tremoço, no Brasil. GTZ, Alemanha.

Galdames, R. e Peñaloza, E. (1999) - Preliminary studies on susceptibility of Lupinus albus and Lupinus angustifolius to anthracnose (Colletotrichum gloeosporioides) in Chile. In: (Hill, G., ed.) - Proceedings of the 8th International Lupin Conference, Asilomar, CA, 11-16 May 1996. pp. 507-511. International Lupin Association, Canterbury, New Zealand.

Gondran, J. (1984a) - Les maladies du lupin blanc doux en France. Perspectives Agricoles, vol. 77, p. :31-41.

Gondran, J. (1984b) - Deux risques de maladie grave pour le développement du lupin blanc doux en France. In: Proceedings of the 3rd International Lupin Conference La Rochelle, 4-8 June 1984. pp. 601-604. La Rochelle, France.

Gondran, J. (1991) - The diseases of white lupin crops in France - prevention possibilities. In: (von Baer, D., ed.) - Proceedings of the 6th International Lupin Conference, Temuco-Pucón, 25-30 November 1990. pp. 277-279. Asociación Chilena del Lupino. Temuco, Chile.

Gondran, J.; Bateman, G.L.; Milford, G.F.J.; Bayer, J.; Beerepoot, L.; Boller, B.; Caligari, P.D.S.; Carrasco López, J.M.; Crowley, J.G.; Rocha, J.J.P.; Feiler, U.; Gataulina, G.G.; Golovchenko, O.V.; Korneichuk, N.S.; Frencel, I.; Jaubertie, J.P.; Jeffes, M.; Jordan, A.C.; Jörnsgaard, B.; Martins, J.M.N.; Mackinaite, R.; Postiglione, L.; Reheul, D.; Römer, P.; Schrems, H.; Szukala, J. e Tello Marquina, J.C. (1999) - Anthracnose of white lupin: european prospects for a sustainable crop. In: (Hill, G., ed.) - Proceedings of the 8th International Lupin Conference, Asilomar, CA, 11-16 May 1996. pp. 512-519. International Lupin Association, Canterbury, New Zealand.

Gondran, J.; Deneufbourg, F. e Vuillaume, E. (1991) - Colletotrichum gloeosporioides of white lupin (biology, seed dressing with chemicals, breeding for resistance). In: (von Baer, D., Ed.) - Proceedings of the 6th International Lupin Conference, Temuco-Pucón, 25-30 November 1990. pp. 322-325. Asociación Chilena del Lupino. Temuco, Chile.

Gondran, J.; Lagattu, C. e Vuillaume, E. (1986) --. Anthracnose (Colletotrichum gloeosporioides Penz) of Lupinus albus and Lupinus mutabilis in France. In: Proceedings of the 4th International Lupin Conference, Geraldton, 1522 August 1986. pp. 40-43. Geraldton, Australia.

Gondran, J. e Pacault, D. (1997). L'anthracnose du lupin blanc. Phytoma, vol. 494, p. 28-31.

Lardner, R.; Johnston, P.; Plummer, K. ePearson, M. (1999)-Morphological and molecular analysis of Colletotrichum acutatum sensu lato. Mycological Research, vol. 103, n. 3, p. 275-285. http://dx.doi.org/10.1017/S0953756298007023 
Lindner, K.; Flath, K.; Garbe, V.; Bartels, G.; Broschewitz, B.; Heidel, W.; Hartleb, H.; Böhlemann, J.; Dittmann, B.; Dittrich, R. e Schmiechen, U. (2000) - The effectiveness of chemical and physical seed treatments to control anthracnose in Lupinus luteus. In: (van Santen, E.; Wink, M.; Weissmann, S. e Römer, P., eds.) Lupin, an ancient crop for the new millennium. Proceedings of the 9th International Lupin Conference, 20-24 June 1999, Klink/Müritz. pp. 57-59. International Lupin Association. Canterbury, New Zealand.

Lotter, H.C. e Berger, D.K. (2005) - Anthracnose of lupins in South Africa is caused by Colletotrichum lupini var. setosum. Australasian Plant Pathology, vol. 34, n. 3, p. 385-392. http://dx.doi.org/10.1071/AP05052

Nirenberg, H.I.; Feiler, U. e Hagedorn, G. (2002) - Description of Colletotrichum lupini comb. nov. in modern terms. Mycologia, vol. 94, n. 2, p. 307-320.

O'Connell, R.J.; Thon, M.R.; Hacquard, S.; Amyotte, S.G.; Kleemann, J.; Torres, M.F.; Damm, U.; Buiate, E.A.; Epstein, L.; Alkan, N.; Altmüller, J.; Alvarado-Balderrama, L.; Bauser, C.A.; Becker, C.; Birren, B.W.; Chen, Z.; Choi, J.; Crouch, J.A.; Duvick, J.P.; Farman, M.A.; Gan, P.; Heiman, D.; Henrissat, B.; Howard, R.J.; Kabbage, M.; Koch, C.; Kracher, B.; Kubo, Y.; Law, A.D.; Lebrun, M.H.; Lee, Y.H.; Miyara, I.; Moore, N.; Neumann, U.; Nordström, K.; Panaccione, D.G.; Panstruga, R.; Place, M.; Proctor, R.H.; Prusky, D.; Rech, G.; Reinhardt, R.; Rollins, J.A.; Rounsley, S.; Schardl, C.L.; Schwartz, D.C.; Shenoy, N.; Shirasu, K.; Sikhakolli, U.R.; Stüber, K.; Sukno, S.A.; Sweigard, J.A.; Takano, Y.; Takahara, H.; Trail, F.; van der Does, H.C.; Voll, L.M.; Will, I.; Young, S.; Zeng, Q.; Zhang, J.; Zhou, S.; Dickman, M.B.; Schulze-Lefert, P.; Ver Loren van Themaat, E.; Ma, L.J. e Vaillancourt, L.J. (2012) - Lifestyle transitions in plant pathogenic Colletotrichum fungi deciphered by genome and transcriptome analyses. Nature Genetics, vol. 44, p. 10601065. http://dx.doi.org/10.1038/ng.2372

Oliveira, M.L. (1955) - Algumas doenças em Lupinus spp. causadas por fungos. Agronomia Lusitana, vol. 17, p. 167-189.

Paulitz, T.C.; Atlin, G. and Gray, A.B. (1995) - First report of Colletotrichum gloeosporioides on lupine in Canada. Plant Disease, vol. 79, p. 319. http://dx.doi.org/10.1094/PD-79-0319D

Perfect, S.E.; Hughes, H.B.; O'Connell, R.J. e Green, J. (1999) - Colletotrichum: a model genus for studies on pathology and fungal-plant interactions. Fungal Genetics and Biology, vol. 27, n. 2-3, p. 186-198. http://dx.doi.org/10.1006/fgbi.1999.1143

Reed, P.J.; Dickens, J.S.W. e O'Neill, T.M. (1996) - Occurrence of anthracnose (Colletotrichum acutatum) on ornamental lupin in the United Kingdom. Plant Pathology, vol. 45, n. 2, p. 245-248. http://dx.doi.org/10.1046/j.1365-3059.1996.d01-131.x

Riegel, R.; Véliz, D.; von Baer, I.; Quitral, Y. e Muñoz, M. (2010) - Genetic diversity and virulence of Colletotrichum lupini isolates collected in Chile. Tropical Plant Pathology, vol. 35, n. 3, p. 144-152. http://dx.doi.org/10.1590/S1982-56762010000300002

Römer, P.; Masutt, K.; Rocha, J.P. e Rocha, M.J. (2000) - Further trials to control anthracnose (Colletotrichum sp.) in white lupins (Lupinus albus) with chemicals. In: (van Santen, E.; Wink, M.; Weissmann, S. \& Römer, P., eds.) - Lupin, an ancient crop for the new millennium. Proceedings of the 9th International Lupin Conference, 20-24 June 1999, Klink/Müritz. pp. 40-42. International Lupin Association. Canterbury, New Zealand.

Semaškienè, R.; Brazauskien, I.; Lisova, R.; Liepien, N. e Maknickien, Z. (2008) - The incidence of anthracnose (Colletotrichum spp.) on lupine seed. Zemdirbyste-Agriculture, vol. 95, n. 3, p. 144-150.

Shea, G.; Cowling, W.A.; Burchell, B.J.; Luckett, D.; Yang, H.; Sweetingham, M.W. e Thomas, G. (1999) Managing lupin anthracnose. Journal of the Department of Agriculture, Western Australia, vol. 40, p. 7.

Shea, G.; Thomas, G.; Buirchell, B.; Salam, M.; McKirdy, S.; Sweetingham, M.; Palta, J. e Berger, J. (2008) Case study: industry response to the lupin anthracnose incursion in Western Australia. In: Proceedings 12th International Lupin Conference, 14-18 September 2008, Fremantle, Australia: 425-431.

Shivas, R.G.; McClements, J.L. e Sweetingham, M.W. (1998) - Vegetative compatibility amongst isolates of Colletotrichum causing lupin anthracnose. Australasian Plant Pathology, vol. 27, n. 4, p. 269-273. http://dx.doi.org/10.1071/AP98032

Sreenivasaprasad, S., Mills, P.R. e Brown, A.E. (1994) - Nucleotide sequence of the rDNA spacer 1 enables identification of isolates of Colletotrichum as C. acutatum. Mycological Research, vol. 98, n. 2, p. 186-188. http://dx.doi.org/10.1016/S0953-7562(09)80184-6 
Sreenivasaprasad, S. e Talhinhas, P. (2005) - Genotypic and phenotypic diversity in Colletotrichum acutatum, a cosmopolitan pathogen causing anthracnose on a wide range of hosts. Molecular Plant Pathology, vol. 6, n.4, p. 361-378. http://dx.doi.org/10.1111/j.1364-3703.2005.00291.x

Sweetingham, M.W.; Cowling, W.A.; Buirchell, B. e Brown, A.G.P. (1998a) - Screening lupins for resistance to anthracnose in New Zealand. In: (Shea, G., ed.) - Highlights of lupin research and development in Western Australia 1998. pp. 10-11. The Chief Executive Officer, Agriculture Western Australia. Australia.

Sweetingham, M.W.; Jones, R.A.C. e Brown, A.G.P. (1998b) - Diseases and pests. In: (Gladstones, J.S.; Atkins, C. e Hamblin, J., Eds.) - Lupins as crop plants: biology, production, and utilization. pp. 263-289. CABI. Oxon, U.K.

Sweetingham, M.W.; Thomas, G.; Yang, H. e Shea, G. (1998c) - Anthracnose - the pathogen, epidemiology and the management package. In: (Shea, G., ed.) - Highlights of lupin research and development in Western Australia 1998. pp. 8-9. The Chief Executive Officer, Agriculture Western Australia. Australia.

Talhinhas, P. (2002) - Caracterização de germoplasma do género Lupinus, avaliação da resistência à antracnose e estudo da diversidade e taxonomia do agente causal (Colletotrichum acutatum Simmonds ex Simmonds). Tese de Doutoramento em Engenharia Agronómica. Instituto Superior de Agronomia (UTL), Lisboa.

Talhinhas, P. (1994). Influência da data de sementeira e do genótipo na produção de Lupinus mutabilis Sweet. Relatório de Licenciatura em Engenharia Agronómica. ISA. Lisboa.

Talhinhas, P.; Baroncelli, R. e Le Floch, G. (2016) - Anthracnose of lupins caused by Colletotrichum lupini: a recent disease and a successful worldwide pathogen. Journal of Plant Pathology, vol. 98, n. 1, p. 5-14. http://dx.doi.org/10.4454/JPP.V9811.040

Talhinhas, P.; Leitão, J. e Neves-Martins, J. (2006) - Collection of Lupinus angustifolius L. germplasm and characterisation of morphological and molecular diversity. Genetic Resources and Crop Evolution, vol. 53, n. 3, p. 563-578. http://dx.doi.org/10.1007/s10722-004-2684-0

Talhinhas, P.; Neves-Martins, J. e Leitão, J. (2003) - AFLP, ISSR and RAPD markers reveal high levels of genetic diversity among Lupinus species. Plant Breeding, vol. 122, n. 6, p. 507-510. http://dx.doi.org/10.1111/j.1439-0523.2003.tb01772.x

Talhinhas, P.; Mota-Capitão, C.; Martins, S.; Ramos, A.P.; Neves-Martins, J.; Guerra-Guimarães, L.; Várzea, V.; Silva, M.C.; Sreenivasaprasad, S. e Oliveira, H. (2011) - Epidemiology, histopathology and aetiology of olive anthracnose caused by Colletotrichum acutatum and C. gloeosporioides in Portugal. Plant Pathology, vol. 60, n. 3, p. 483-495. http://dx.doi.org/10.1111/j.1365-3059.2010.02397.x

Talhinhas, P.; Sreenivasaprasad, S.; Neves-Martins, J. e Oliveira, H. (2002) - Genetic and morphological characterisation of Colletotrichum acutatum causing anthracnose of lupins. Phytopathology, vol. 92, n. 9, p. 986-996. http://dx.doi.org/10.1094/PHYTO.2002.92.9.986

Thomas, G. e Sweetingham, M. (1998) - Fungicide seed dressings for lupin anthracnose. In: (Shea, G., ed.) Highlights of lupin research and development in Western Australia 1998. pp. 5-7. The Chief Executive Officer, Agriculture Western Australia. Australia.

Thomas, G. e Sweetingham, M. (2000) - Storage effects on C. gloeosporioides infection levels in lupin seed. In Lupin, an ancient crop for the new millennium. In: (van Santen, E.; Wink, M.; Weissmann, S. \& Römer, P., eds.) - Proceedings of the 9th International Lupin Conference, 20-24 June 1999, Klink/Müritz. pp. 33-36. International Lupin Association. Canterbury, New Zealand.

Thomas, G.J. e Sweetingham, M.W. (2004) - Cultivar and environment influence the development of lupin anthracnose caused by Colletotrichum lupini. Australasian Plant Pathology, vol. 33, n. 4, p. 571-577. http://dx.doi.org/10.1071/AP04060

Thomas, G.J.; Sweetingham, M.W.; Yang, H.A. e Speijers, J. (2008) - Effect of temperature on growth of Colletotrichum lupini and on anthracnose infection and resistance in lupins. Australasian Plant Pathology, vol. 37, n. 1, p. 35-39. http://dx.doi.org/10.1071/AP07075

Tu, J.C. (1986) - A detached leaf technique for screening beans (Phaseolus vulgaris L.) in vitro against anthracnose (Colletotrichum lindemuthianum). Canadian Journal of Plant Sciences, vol. 66, n. 3, p. 805-809. http://dx.doi.org/10.4141/cjps86-100

van der Mey, J.; McDonald, A. e Boulter, M. (1996) - Siektewaarskuwing op lupiene. Luptec, vol. 17, p. 1-4. 
van der Mey, J.; van Wyk, P.S. e Römer, P. (2000) - Selection for resistance against Colletotrichum gloeosporioides or anthracnose in Lupinus albus for the summer rainfall areas of South Africa. In: (van Santen, E.; Wink, M.; Weissmann, S. e Römer, P., eds.) - Lupin, an ancient crop for the new millennium. Proceedings of the 9th International Lupin Conference, 20-24 June 1999, Klink/Müritz. pp. 23-25. International Lupin Association. Canterbury, New Zealand.

von Baer, E. \& Hashagen, U. (1999) - Living with anthracnose. In: (Hill, G., ed.) - Proceedings of the 8th International Lupin Conference, Asilomar, CA, 11-16 May 1996. pp. 497-501. International Lupin Association, Canterbury, New Zealand.

Weidemann, G.J.; TeBeest, D.O. e Cartwright, R.D. (1988) - Host specificity of Colletotrichum gloeosporioides f. sp. aeschynomene and C. truncatum in the Leguminosae. Phytopathology, vol. 78, n. 6, p. 986-990. http://dx.doi.org/10.1094/Phyto-78-986

Weimer, J.L. (1943) - Anthracnose of Lupines. Phytopathology, vol. 33, p. 249-252.

Weimer, J.L. (1952) - Lupine anthracnose. United States Department of Agriculture, circular n. 904, August 1952. Washington DC, USA.

Weimer, J.L. e Dunegan, J.C. (1949) - Identity of anthracnose of lupine and peach caused by Glomerella cingulata. Plant Disease Reporter, vol. 33, p. 416-418.

Wells, H.D. \& Forbes, I. (1967) - Effects of temperature on growth of Glomerella cingulata in vitro and on its pathogenicity to Lupinus angustifolius genotypes an an and An An. Phytopathology, vol. 57, p. 1309-1311.

Welty, R. (1984) - Blues lupine as a host for Colletotrichum trifolii from alfalfa and for C. fragariae from strawberry. Plant Disease, vol. 68, n. 2, p. 142-144. http://dx.doi.org/10.1094/PD-68-142 